\title{
REVIEW
}

\section{Biomedical Applications of the Dynamic Nuclear Polarization and Parahydrogen Induced Polarization Techniques for Hyperpolarized ${ }^{13} \mathrm{C}$ MR Imaging}

\author{
Neil J. Stewart and Shingo Matsumoto*
}

\begin{abstract}
Since the first pioneering report of hyperpolarized $\left[1-{ }^{13} \mathrm{C}\right]$ pyruvate magnetic resonance imaging (MRI) of the Warburg effect in prostate cancer patients, clinical dissemination of the technique has been rapid; close to 10 sites worldwide now possess a polarizer fit for the clinic, and more than 30 clinical trials, predominantly for oncological applications, are already registered on the US and European clinical trials databases. Hyperpolarized ${ }^{13} \mathrm{C}$ probes to study pathophysiological processes beyond the Warburg effect, including tricarboxylic acid cycle metabolism, intra-cellular $\mathrm{pH}$ and cellular necrosis have also been demonstrated in the preclinical arena and are pending clinical translation, and the simultaneous injection of multiple co-polarized agents is opening the door to high-sensitivity, multi-functional molecular MRI with a single dose. Here, we review the biomedical applications to date of the two polarization methods that have been used for in vivo hyperpolarized ${ }^{13} \mathrm{C}$ molecular MRI; namely, dissolution dynamic nuclear polarization and parahydrogeninduced polarization. The basic concept of hyperpolarization and the fundamental theory underpinning these two key ${ }^{13} \mathrm{C}$ hyperpolarization methods, along with recent technological advances that have facilitated biomedical realization, are also covered.
\end{abstract}

Keywords: ${ }^{13} \mathrm{C}$ metabolic MRI, dynamic nuclear polarization, hyperpolarization, molecular imaging, parahydrogen-induced polarization

\section{Introduction}

Hyperpolarization refers to a class of methods that enable the fundamental sensitivity limits of magnetic resonance imaging (MRI) to be overcome, allowing functional imaging of exogenous agents of unprecedented quality. ${ }^{1}$ Over the last 20 years, hyperpolarized (HP) ${ }^{3} \mathrm{He}$ and ${ }^{129} \mathrm{Xe}$ noble gases have been developed from experimental tools into safe, inhalable contrast agents for high-resolution, functional MRI of the lung airspaces and are already used routinely in a clinical setting. ${ }^{2}$ On the other hand, $\mathrm{HP}{ }^{13} \mathrm{C}$-labelled liquid-phase probes for molecular and metabolic MRI hold great promise for interrogating pathophysiology at the cellular level. ${ }^{3}$

Division of Bioengineering and Bioinformatics, Graduate School of Information Science and Technology, Hokkaido University, Hokkaido, Japan

${ }^{*}$ Corresponding author: Division of Bioengineering and Bioinformatics, Graduate School of Information Science and Technology, Hokkaido University, Sapporo Hokkaido 060-0814, Japan. Phone: +81-11-706-6789, Fax: +81-11-706-6802, E-mail: smatsumoto@ist.hokudai.ac.jp

(C)2019 Japanese Society for Magnetic Resonance in Medicine

This work is licensed under a Creative Commons Attribution-NonCommercialNoDerivatives International License.

Received: August 21, 2019 | Accepted: November 4, 2019
The first in-man hyperpolarized $\left[1-{ }^{13} \mathrm{C}\right]$ pyruvate MRI exams in patients with prostate cancer realized the potential for observing metabolic processes beyond glycolysis, which is typically probed by ${ }^{18} \mathrm{~F}$-fluorodeoxyglucose positron-emission tomography $\left({ }^{18} \mathrm{~F}\right.$-FDG-PET); until recently the only metabolic imaging method used routinely in the oncology clinic. ${ }^{4}$ This pioneering study has been followed by a rapid dissemination of HP $\left[1-{ }^{13} \mathrm{C}\right]$ pyruvate MRI for clinical applications, ${ }^{5}$ facilitated by the development of commercial, sterile polarization systems for clinical use. ${ }^{6}$ As of June 2019 , more than 30 clinical trials worldwide pertaining to $\mathrm{HP}\left[1-{ }^{13} \mathrm{C}\right]$ pyruvate MRI are either in a complete, in progress, or pending phase and this number is predicted to only increase further over the coming years.

In this review article, we provide a brief overview of the concept of hyperpolarization and the theory behind the methods to obtain liquid-state ${ }^{13} \mathrm{C}$ polarization; namely, dissolution dynamic nuclear polarization (d-DNP) and parahydrogen-induced polarization (PHIP), followed by a comprehensive review of the biomedical applications of HP ${ }^{13} \mathrm{C}$ MRI by, with a particular focus on recent clinical MRI applications of HP $\left[1-{ }^{13} \mathrm{C}\right]$ pyruvate and other hyperpolarized ${ }^{13} \mathrm{C}$ molecular imaging probes with clinical promise. 


\section{Theoretical Background}

\section{Hyperpolarization}

When placed in a magnetic field $B_{0}$, spin- $1 / 2$ nuclei of gyromagnetic ratio $\gamma$ occupy one of two Zeeman states at energies $\pm \gamma \hbar B_{0} / 2$. The nuclear spin "polarization" is defined as the fractional difference in the population of the two states, which under conditions of thermal equilibrium is derived from the Boltzmann distribution:

$$
P=\tan h\left(\frac{\Delta E}{2 k_{B} T}\right) \approx\left(\frac{\gamma \hbar B_{0}}{2 k_{B} T}\right)
$$

The Boltzmann (thermal) polarization of ${ }^{13} \mathrm{C}$ - the only stable spin- $1 / 2$ carbon nucleus - at typical clinical magnetic field strengths is $\sim 10^{-6}$. In fact, MR of endogenous ${ }^{13} \mathrm{C}$ is challenging not just due to its $\sim$ fourfold lower gyromagnetic ratio than ${ }^{1} \mathrm{H}$; the natural abundance of ${ }^{13} \mathrm{C}$ is only $1.1 \%$ and thus sensitivity is poor. A 100-fold MR signal enhancement can be obtained on endogenous tracers through ${ }^{13} \mathrm{C}$-labeling, and a further 4-5 orders of magnitude enhancement via hyperpolarization.

Hyperpolarization denotes a temporary state of dramatic population excess in one nuclear spin state (see Fig. 1) and can be realized by a number of approaches; brute force polarization (utilizing low temperatures and high magnetic fields to directly increase the nuclear polarization) $)^{7,8}$; spin-exchange optical pumping 9 and metastability-exchange optical pumping ${ }^{10}$ for hyperpolarized gases; and d-DNP ${ }^{11}$ and $\mathrm{PHIP}^{12}$ for solution-state ${ }^{13} \mathrm{C}$ applications. The latter two methods have been demonstrated for biomedical ${ }^{13} \mathrm{C}$ molecular MRI a) Thermal polarization

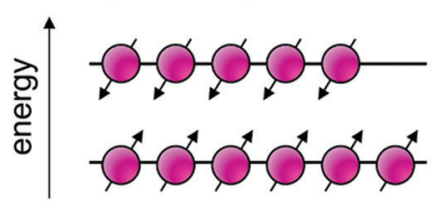

$232 k$

averages b) Hyperpolarization

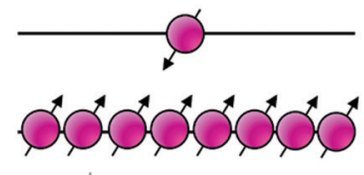

1 scan

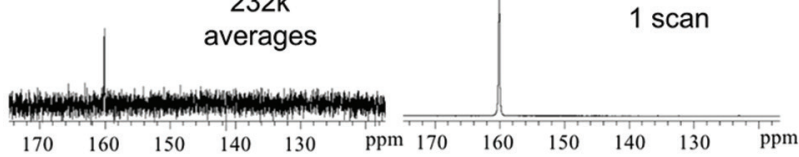

Fig. 1 Concept of hyperpolarization. (a) The occupation of nuclear Zeeman states of a spin- $1 \frac{1}{2}$ system in thermal equilibrium in a magnetic field follows that of the Boltzmann distribution [cf. Equation (1)]; for ${ }^{13} \mathrm{C}$ at $1.5 \mathrm{~T}$ and $300 \mathrm{~K}$, the polarization, i.e. the population difference between the spin up and down states for ${ }^{13} \mathrm{C}$ is only $P \sim 10^{-6}$. (b) Hyperpolarization describes the state of a large excess population in one of the nuclear Zeeman states, leading to a nuclear polarization several orders of magnitude greater than the Boltzmann polarization (Data is reproduced from the original dissolution dynamic nuclear polarization (d-DNP) paper ${ }^{11}$ (Copyright (2003) National Academy of Sciences, USA) and compares NMR spectra obtained from thermally-polarized and hyperpolarized ${ }^{13} \mathrm{C}$ urea of $\sim 60 \mathrm{mM}$ concentration). applications and these form the focus of this review article. We note that signal amplification by reversible exchange (SABRE), ${ }^{13}$ closely-related to conventional PHIP, is recently showing progress toward potential in vivo application ${ }^{14}$ but will not be covered in this article as biomedical application is yet to be shown; we refer the reader to Robertson and Mewis ${ }^{15}$ for an up-to-date review.

The MR signal enhancement associated with hyperpolarization is not permanent; longitudinal relaxation acts to return the nuclear spin state populations to that of thermal equilibrium, and after radiofrequency excitation, the hyperpolarized state is not recovered. ${ }^{16}$ Research into generating so-called "long-lived" states and also generation of continuously re-hyperpolarization ${ }^{17}$ are an active fields ${ }^{18}$; however, hyperpolarized $\left[1-{ }^{13} \mathrm{C}\right]$ pyruvate, the most promising molecule for clinical applications, remains limited by a $T_{1} \sim 60 \mathrm{~s}$. The decay in magnetization associated with a number of RF excitations $n$ with repetition time TR and flip angle $\alpha$ can be described as follows:

$$
M_{x y}(n)=M_{0} \exp \left[-(n-1) \frac{T R}{T_{1}}\right] \sin \left(\alpha_{n}\right) \prod_{j=1}^{n-1} \cos \left(\alpha_{j}\right)
$$

For a constant flip angle, and $T R<<T_{1}$, Equation (2) can be simplified to $M_{x y}(n)=M_{0} \sin (\alpha) \cos ^{n-1}(\alpha)$ [for example, after $N=128 \mathrm{RF}$ excitations at flip angle $8^{\circ}$ a magnetization of only $M_{x y}(N) \approx 0.3 M_{0} \sin \left(8^{\circ}\right)$ remains]. The signal decay during acquisition leads to filtering of the $k$-space and image blurring, but which can be somewhat compensated for by modifying the flip angle throughout the acquisition process. ${ }^{16,19}$ Nevertheless, acquisition of hyperpolarized signals necessitates efficient encoding of $k$-space, such as with spiral trajectories, ${ }^{20}$ parallel imaging ${ }^{21}$ or compressed sensing. ${ }^{22}$ Hyperpolarized ${ }^{13} \mathrm{C}$ metabolic MRI relies upon the discrimination of MR signals from the injected probe (e.g. pyruvate) and its metabolic products (e.g. lactate) by chemical shift. If spatial information is not essential, dynamic spectroscopy is a simple and robust means to probe metabolism dynamics. ${ }^{23}$ Several imaging strategies have been developed ${ }^{24}$ including: phaseencoded chemical shift imaging (CSI). ${ }^{25}$ which although inefficient, allows acquisition of full spectra; echo planar spectroscopic imaging, in which (usually fly-back) gradients are used for simultaneous 1D spatial encoding and spectral readout, permitting several-fold acceleration at the expense of SNR; ${ }^{26,27}$ spiral chemical shift imaging, wherein multi-dimensional spatial data is encoded simultaneously with spectral data in a similar manner to tomosynthesis; ${ }^{28}$ spiral encoding schemes $^{29}$ combined with the robust iterative decomposition with echo asymmetry and least-squares estimation technique; ${ }^{30}$ and spectral-spatial excitation for additional efficiency and the flexibility of a different flip angle on each resonance of interest. ${ }^{31}$ In light of the long $\mathrm{T}_{2}$ of ${ }^{13} \mathrm{C}$ in vivo, SNR benefits have been realized by using single or multi-echo balanced steady-state free precession. ${ }^{32,33}$ 


\section{Dynamic nuclear polarization}

Dissolution dynamic nuclear polarization - to date the principal polarization techniques employed to generate hyperpolarized $\left[1-{ }^{13} \mathrm{C}\right]$ pyruvate - relies upon the relatively large electron gyromagnetic ratio $\left(\gamma_{e} \approx 660 \gamma_{P}\right)$ which [according to Equation (1)] leads to an electron Boltzmann polarization of approximately unity at temperatures $\sim 1 \mathrm{~K}$ at high field (see Fig. 2a).$^{34}$ An efficient electron paramagnetic agent (free radical, see e.g. Lumata et al..$^{35}$ ) is mixed with a glassing agent and the target probe to be polarized (e.g. pyruvate), which is cooled to $\sim 1 \mathrm{~K}$ under a magnetic field of several tesla. In the subsequent glassy solid state where d-DNP is most efficient, microwave irradiation is used to induce polarization transfer from free electrons to ${ }^{13} \mathrm{C}$ nuclei over the course of $\sim 1 \mathrm{~h}$. At temperatures $<4.2 \mathrm{~K}$, polarization transfer is believed to be primarily driven by the thermal mixing effect, ${ }^{36}$ though depending on exact experimental conditions, contributions from the so-called solid effect and cross effect, ${ }^{37}$ and the Overhauser effect in the solution phase, ${ }^{38}$ may not be ignored. After polarization transfer, the frozen sample is rapidly dissolved in a superheated solvent and transferred to the MRI system for measurement [hence the term "dissolution (d)" "11].

The first commercial d-DNP system for preclinical research applications shortly followed the publication of the original d-DNP paper ${ }^{11}$ (HyperSense, Oxford Instruments, UK) and other efficient research systems have since been developed. ${ }^{39}$ Most d-DNP systems including the HyperSense require large quantities of liquid helium to maintain the low sample temperature; however, two recent landmark developments have enabled d-DNP without consumption of cryogens; a high-throughput, sterile polarizer for clinical applications SpinLab ${ }^{6}$ (GE Healthcare, Waukesha, WI, USA), and an efficient research polarizer with variable magnetic field (the SpinAligner, (Polarize, Frederiksberg, Denmark) $),{ }^{40}$ both of which are commercially available. The SpinLab (Fig. 2a), operating at $\sim 0.9 \mathrm{~K}$ and $5 \mathrm{~T}$ and routinely obtaining up to $40 \%\left[1-{ }^{13} \mathrm{C}\right]$ pyruvate polarization, is the only system to date approved for human application. i)
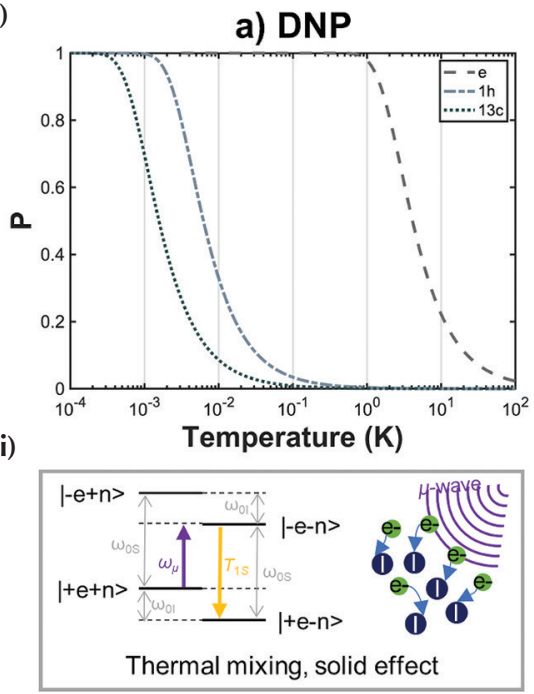

iii)

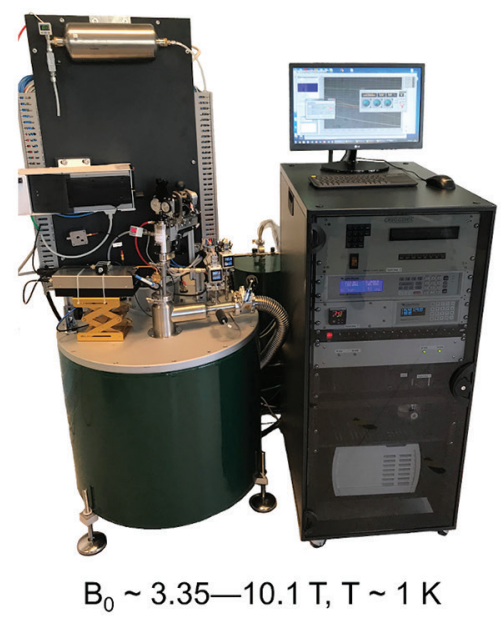

b) PHIP
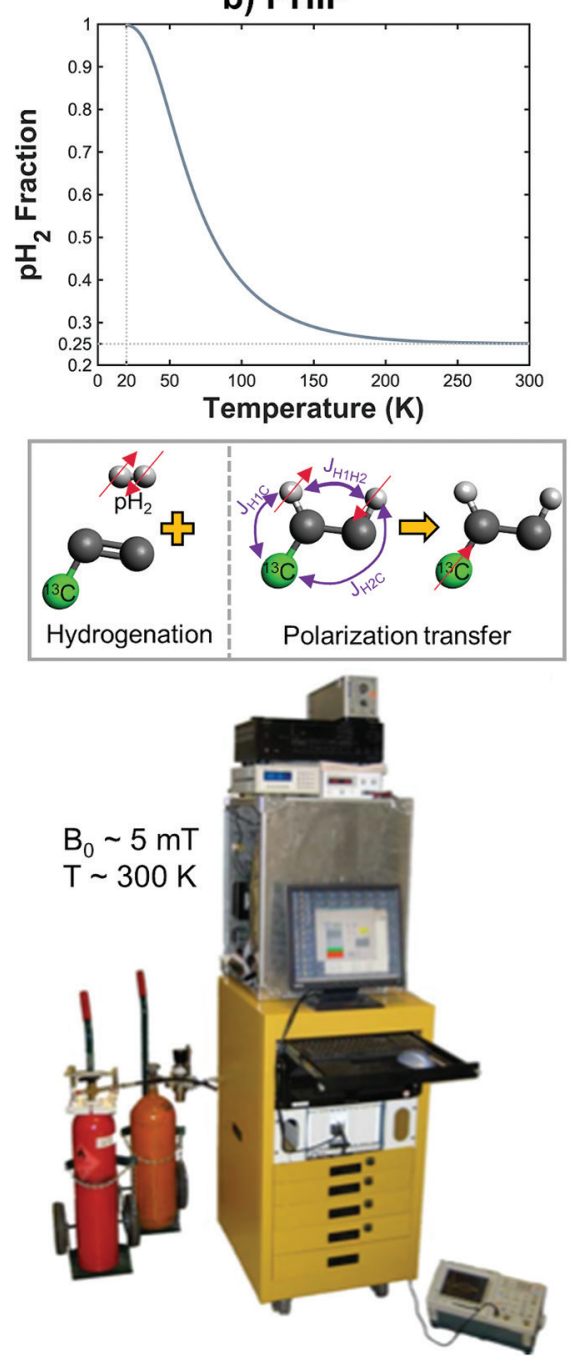

Fig. 2 Concept diagram for dissolution dynamic nuclear polarization (d-DNP) and parahydrogen-induced polarization (PHIP) polarization techniques. (a) In $\mathrm{d}$-DNP, the source of ${ }^{13} \mathrm{C}$ nuclear polarization $(\mathrm{P})$ is the approximately unity electron polarization $(\mathrm{P})$ at low temperature and high magnetic field (curves plotted for 3.35T) (i). This is transferred to ${ }^{13} \mathrm{C}$ via microwave excitation (ii), predominantly mediated via the thermal mixing effect. (iii) Prototype commercial cryogen-free d-DNP system reported in ArdenkjaerLarsen et al. ${ }^{40}$ (original photo courtesy of Jan Henrik Ardenkjaer-Larsen, Technical University of Denmark and GE Healthcare). (b) In PHIP, the source of ${ }^{13} \mathrm{C}$ polarization is the inherent spin order of the parahydrogen spin isomer of hydrogen, which can be generated to very high purity by cooling normal hydrogen in the presence of a paramagnetic catalyst (i). Parahydrogen is reacted with an unsaturated substrate, generating ${ }^{1} \mathrm{H}$ hyperpolarization, which is subsequently transferred to ${ }^{13} \mathrm{C}$ or other target heteronucleus (ii). Several dedicated low-field (mT) polarization systems have been designed for automating the hydrogenation and polarization transfer processes; the example shown is reprinted with permission from Springer Nature (Hövener et al). ${ }^{58}$ 


\section{Parahydrogen-induced polarization}

Despite surmounting the hurdle associated with cryogen consumption, the initial outlay required for d-DNP systems remains high ( $\sim$ several million USD for the SpinLab). PHIP ${ }^{12}$ is a relatively recent technique that offers a cheaper route to hyperpolarized ${ }^{13} \mathrm{C}$ molecules for biomedical MRI applications. ${ }^{41}$ PHIP relies on the inherent spin order of parahydrogen, a spin isomer of hydrogen. At room temperature, the two spin- $1 \frac{1}{2}$ nuclei of each hydrogen molecule have an equal probability to occupy one of four spin states; three states of total spin 1 (orthohydrogen, "triplet" state) and one state of total spin 0 (parahydrogen, "singlet" state). When cooled in the presence of a paramagnetic catalyst (typically iron(III) oxide or charcoal, which promotes the otherwise slow symmetry-forbidden transition between orthohydrogen and the lower energy parahydrogen state) to $\sim 20 \mathrm{~K}$, a parahydrogen fraction of $\sim 1$ can be obtained (see Fig. $2 b$ ).

Parahydrogen itself is NMR silent since it has a total nuclear spin of 0 ; however, upon pairwise addition to magnetically-inequivalent sites on an unsaturated substrate molecule, the symmetry of the parahydrogen singlet state is broken and hyperpolarized ${ }^{1} \mathrm{H}$ MR signals can be observed. This hydrogenation reaction is typically performed in an organic solvent or the aqueous phase in the presence of a transition metal (typically Rh- or Ru-)based catalyst. ${ }^{42}$ The resulting ${ }^{1} \mathrm{H}$ nuclear spin state depends on the magnetic field at which parahydrogen addition is performed; at high field, e.g. within the MR system itself, the parahydrogen and synthesis allow dramatically enhanced nuclear alignment effect is observed, ${ }^{12}$ whilst for hydrogenation at low field followed by adiabatic transport of the sample to the MR system for detection, the adiabatic longitudinal transport after dissociation engenders nuclear alignment effect is observed. ${ }^{43} \mathrm{Sev}-$ eral studies using PHIP of ${ }^{1} \mathrm{H}$ nuclei have been performed (e.g. to generate J-coupling derived contrast ${ }^{44}$ and gas-phase imaging ${ }^{45}$ ); however, due to the large background signal in vivo and lack of attainable pathophysiological functional information such as that pertaining to metabolism, heteronuclei such as ${ }^{13} \mathrm{C}$ or ${ }^{15} \mathrm{~N}$ are of greater interest for biomedical applications. Polarization transfer from ${ }^{1} \mathrm{H}$ to heteronuclei is mediated by spin-spin couplings and can be driven by specialized RF pulse sequences ${ }^{46-48}$ or by subjecting the sample to a magnetic field cycle. ${ }^{49-51}$ The selection of polarization transfer method and its parameters depends on the configuration of the target molecular probe..$^{52,53}$

Regarding hardware, parahydrogen enrichment of $\sim 50 \%$ can be achieved by simply flowing hydrogen gas through a cryogenic tube submersed in liquid nitrogen. ${ }^{54} \mathrm{~A}$ highthroughput system to generate and store up to 50 bar of $98 \%$ parahydrogen has been developed for biomedical applications ${ }^{55}$; once stored, parahydrogen enrichment can be maintained for months provided that paramagnetic molecular oxygen is not present. ${ }^{56}$ Several automated PHIP polarizers for low-field hydrogenation and polarization transfer have been developed ${ }^{57-59}$ incorporating heated, high-pressure spray reactors; however, promising results have also been obtained by simply shaking or bubbling of a parahydrogenfilled NMR tube followed by field cycling by hand (see e.g. Chukanov et al. ${ }^{60}$ ). In addition, unlike d-DNP, it is possible to perform both the hydrogenation reaction and polarization transfer and generate heteronuclear hyperpolarization within the NMR magnet itself, minimizing the time for polarization decay. ${ }^{46,61}$

\section{d-DNP-polarized [1- ${ }^{13}$ C]pyruvate: the pathway to clinical application}

Abnormal metabolism is a hallmark of cancer, cardiovascular disease and other pathologies, and is intrinsically linked to inflammation and immune response. ${ }^{62}{ }^{18} \mathrm{~F}$ fluorodeoxyglucose (FDG), a glucose analog, is routinely used for highsensitivity and specificity clinical PET imaging of glucose metabolism ${ }^{63}$ and is the recommended clinical indicator for head, neck, lung and pancreatic cancer. ${ }^{64}$ However, since FDG-6-phosphate does not undergo further glycolysis, FDGPET cannot probe metabolism beyond the first step of the glycolysis pathway. In this respect, d-DNP of $\left[1-{ }^{13} \mathrm{C}\right]$ pyruvate represents a significant development permitting unprecedented access to downstream metabolites to further aid understanding of cancer and disease mechanisms.

Whilst the first in vivo studies of a molecule polarization by d-DNP were performed with $\mathrm{HP}{ }^{13} \mathrm{C}$-urea, ${ }^{65}$ it was quickly realized that $\left[1-{ }^{13} \mathrm{C}\right]$ pyruvate, which plays a critical role in metabolism (see Fig. 3), is an ideal molecule for d-DNP since it is self-glassy and has long $\mathrm{T}_{1}$ for ${ }^{13} \mathrm{C}$ at the 1 and 2 positions ( $40-60$ s). ${ }^{66}$ Golman et al. ${ }^{67}$ demonstrated the first real-time metabolic imaging of metabolic production of $\left[1-{ }^{13} \mathrm{C}\right]$ lactate, $\left[1-{ }^{13} \mathrm{C}\right]$ alanine and $\left[1-{ }^{13} \mathrm{C}\right]$ bicarbonate from hyperpolarized $\left[1-{ }^{13} \mathrm{C}\right]$ pyruvate in healthy rats and pigs, and demonstrated differences in metabolite signal intensity in tumor tissues. ${ }^{68} \mathrm{In}$ cancer cells, glycolysis prevails over oxidative phosphorylation and the conversion of pyruvate to lactate via lactate dehydrogenase is up-regulated; this is known as the Warburg effect. ${ }^{69}$ To date, increased HP $\left[1-{ }^{13} \mathrm{C}\right]$ pyruvate to $\left[1-{ }^{13} \mathrm{C}\right] \mathrm{lac}-$ tate conversion has been used as the principal outcome of HP $\left[1-{ }^{13} \mathrm{C}\right]$ pyruvate MRI studies in several types of cancers. ${ }^{68,70-73}$ The high sensitivity of HP $\left[1-{ }^{13} \mathrm{C}\right]$ pyruvate MRI affords the possibility of non-invasive assessment of cancer treatment response, first demonstrated by Day et al., ${ }^{74}$ who showed a decrease in of $\mathrm{HP}{ }^{13} \mathrm{C}$ pyruvate-lactate flux after chemotherapy. The technique has since been applied in several studies of radiotherapy response $\mathrm{s}^{75,76}$ and assessment of other treatments $\mathrm{s}^{77,78}$ and reported to present a viable clinical alternative to FDGPET for early tumor response in a preclinical study. ${ }^{79}$

In a landmark paper, Nelson et al. reported the utilization of GE's prototype sterile d-DNP system ${ }^{6}$ to perform the first in-man HP $\left[1-{ }^{13} \mathrm{C}\right]$ pyruvate MR spectroscopy and imaging feasibility study of patients with prostate cancer, ${ }^{4}$ demonstrating distinction of high- and low-grade tumors. This development has opened the door to realize real-time clinical metabolic imaging with HP $\left[1-{ }^{13} \mathrm{C}\right]$ pyruvate and the rapid 


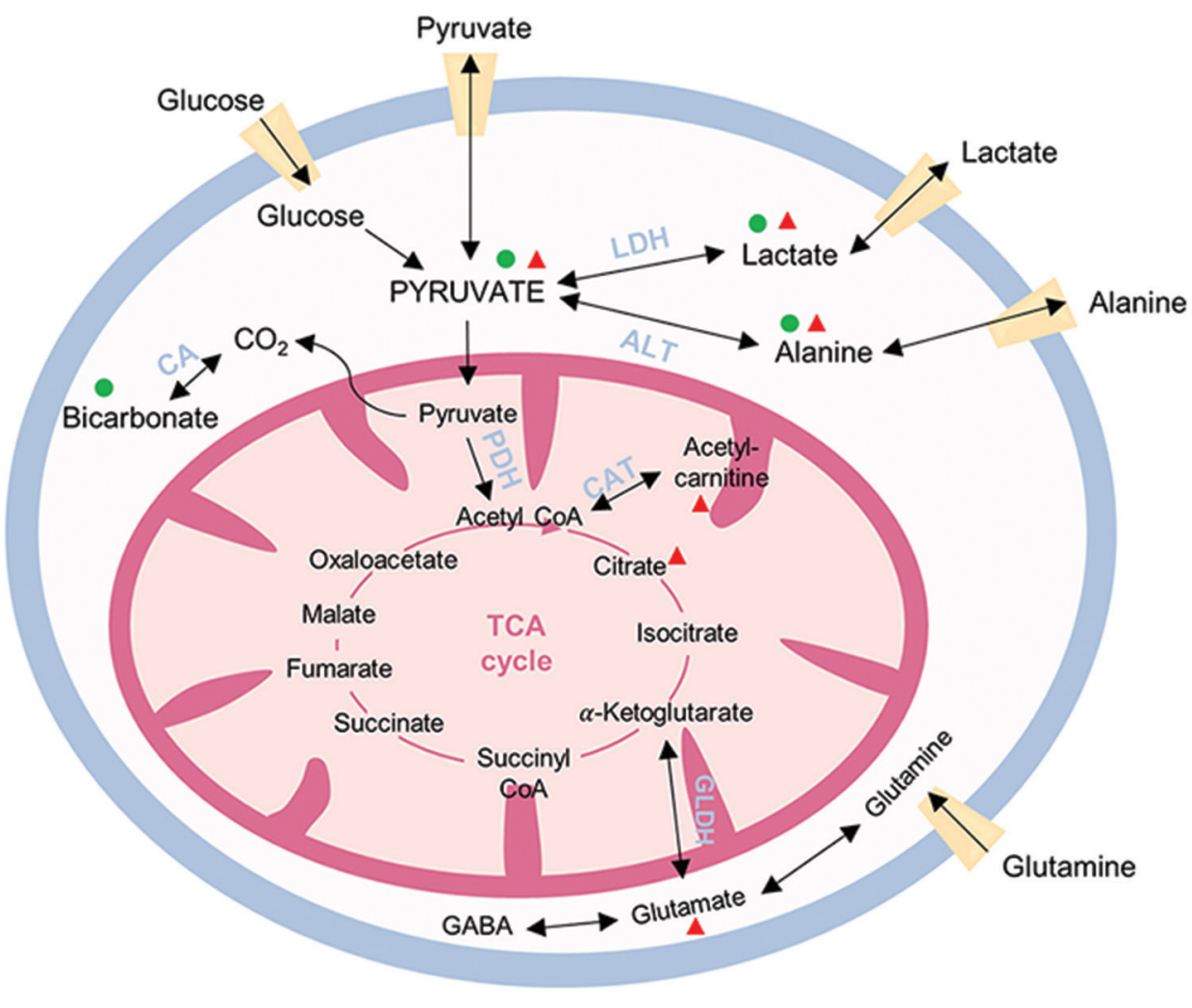

Fig. 3 Schematic of glycolysis, pyruvate metabolism to alanine and lactate, and the tricarboxylic acid (TCA) cycle within the mitochondria. Green circles: products of $\left[1-{ }^{13} \mathrm{C}\right]$ pyruvate; red triangles: products of $\left[2-{ }^{13} \mathrm{C}\right]$ pyruvate. uptake of the technology is epitomized by the fact that more than 20 GE SpinLab polarizers have been installed worldwide, with close to half presently in use for human studies. First reports of the application of $\left[1-{ }^{13} \mathrm{C}\right]$ pyruvate to study metabolism in the healthy human heart ${ }^{80}$ and brain ${ }^{81}$ have reported good tolerance of the procedure and contributed valuable reference data for interpretation of patient studies. In prostate cancer, HP $\left[1-{ }^{13} \mathrm{C}\right]$ pyruvate has been shown to detect early response to androgen deprivation therapy with a sensitivity exceeding that of $\mathrm{T}_{2}$ - and diffusion-weighted MRI. ${ }^{82}$ Preliminary reports in patients with liver metastases ${ }^{83}$ and those with brain tumors ${ }^{84,85}$ demonstrate the wide range of potential targets of the technology and provide important pilot data for future trials. Several of these early clinical results are summarized in Fig. 4. Furthermore, at the 2019 International Society for Magnetic Resonance in Medicine (ISMRM) meeting, first HP $\left[1-{ }^{13} \mathrm{C}\right]$ pyruvate data in human patients with breast cancer, in which the relationship between intertumoral heterogeneity and gene expression analysis was investigated, ${ }^{86}$ and preliminary longitudinal HP $\left[1-{ }^{13} \mathrm{C}\right]$ pyruvate data in glioma patients ${ }^{87,88}$ was reported, highlighting the advantages of the non-invasive nature of the technique for short- and long-term patient follow-up. Moreover, more than 30 clinical trials (sum of completed, ongoing and pending trials) are registered on the US and European clinical trials registries (summarized in Table 1) targeting a range of conditions, including prostate, brain, breast, ovarian, uterine, pancreatic and skin cancers, in addition to cardiovascular indications and other brain pathologies. Comparison with FDG-PET to further comprehend the complementary information that can be obtained ${ }^{89,90}$ is a critical next step to aid interpretation of human HP $\left[1-{ }^{13} \mathrm{C}\right]$ pyruvate data and encourage further clinical dissemination.

As the number of clinical studies with $\left[1-{ }^{13} \mathrm{C}\right]$ pyruvate increases, there is a growing need for robust quantitation methods that can be applied universally for multi-site validation studies. ${ }^{91}$ Typically, HP $\left[1-{ }^{13} \mathrm{C}\right]$ pyruvate MR examinations include dynamic spectroscopy of the time-course of metabolic conversion of pyruvate, in addition to imaging. Semi-quantitative analysis of metabolic dynamics measured by MR spectroscopy can be performed using one of several models that have been developed to describe the rate of pyruvate-lactate conversion $k_{P L}{ }^{92}$ For the most simple two-compartment model of pyruvate-lactate conversion, written in matrix form (see e.g. Harrison et al. ${ }^{92}$ and Harris et al. ${ }^{93}$ ):

$$
\frac{d}{d t}\left[\begin{array}{l}
P_{z} \\
L_{z}
\end{array}\right]=\left[\begin{array}{cc}
-k_{P L}-\rho_{P} & k_{L P} \\
k_{P L} & -k_{L P}-\rho_{L}
\end{array}\right]\left[\begin{array}{c}
P_{z} \\
L_{z}
\end{array}\right]
$$

where $P_{Z}$ and $L_{Z}$ are the $z$-magnetization of pyruvate and lactate, respectively, $k_{L P}$ is the (reverse) lactate-pyruvate conversion rate and $\rho_{i}=1 / T_{1, i}-\log (\cos (\alpha)) /$ TR describes $\mathrm{T}_{1}$ relaxation and $\mathrm{RF}$-induced depolarization [cf. Equation (2)]. This equation can be analytically ${ }^{74}$ or numerically solved and utilized to fit the magnetic resonance spectroscopy 
(MRS) signal intensities of lactate and pyruvate (see for example the data in Fig. $4 \mathrm{a}$ ) to yield $k_{P L}$ as a metric of the Warburg effect. Model-free approaches such as the area under the signal-time curve and time-to-peak present simple, robust alternatives. ${ }^{91}$ CSI-based techniques yield individual images for each metabolic product, and ratio maps of lactate to pyruvate signal intensity are commonly used to provide some degree of quantitation in a regional manner.

\section{d-DNP beyond [1-13 C]pyruvate: other candidate molecular probes}

The range of molecular imaging targets that can be polarized by d-DNP is vast and an exhaustive list ${ }^{94}$ is beyond the scope of the present article. In the following, we introduce several of the most promising d-DNP-polarizable ${ }^{13} \mathrm{C}$ molecular probes for biomedical applications (see Table 2 for a summary).
While the large majority of pre-clinical and clinical studies to date have exploited the sensitivity of HP $\left[1-{ }^{13} \mathrm{C}\right]$ pyruvate to the Warburg effect (i.e. pyruvate-lactate metabolism), the $\mathrm{C}_{1}$ atom of the remaining pyruvate that enters into the mitochondria is oxidized to $\mathrm{CO}_{2}$ and subsequently converted to bicarbonate, and thus cannot be used to probe tricarboxylic acid (TCA) cycle metabolism. However, the $\mathrm{C}_{2}$ atom passes to acetyl-CoA and enters into the TCA cycle, exhibiting several metabolic fates (Figs. 3 and 5b). Schroeder et al. ${ }^{23}$ first reported detection of downstream metabolites including $\left[1-{ }^{13} \mathrm{C}\right]$ acetylcarnitine, $\left[1-{ }^{13} \mathrm{C}\right]$ citrate, $\left[5-{ }^{13} \mathrm{C}\right]$ glutamate in perfused rat hearts after injection of $\mathrm{HP}\left[2-{ }^{13} \mathrm{C}\right]$ pyruvate, with decreased citrate and glutamate production post-ischemia. In response to rapid pacing challenge, in vivo measurements of cardiac metabolism showed increased $\left[5-{ }^{13} \mathrm{C}\right]$ glutamate production, ${ }^{95}$ and increased glutamate, a

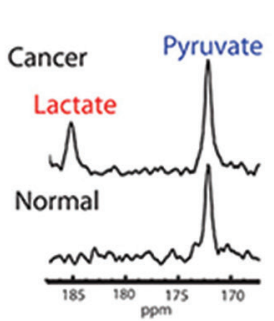

Prostate cancer region

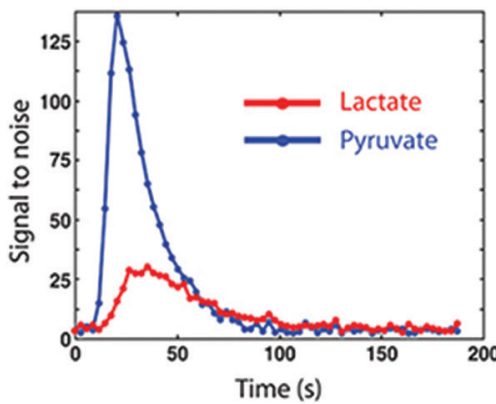

Contralateral prostate region

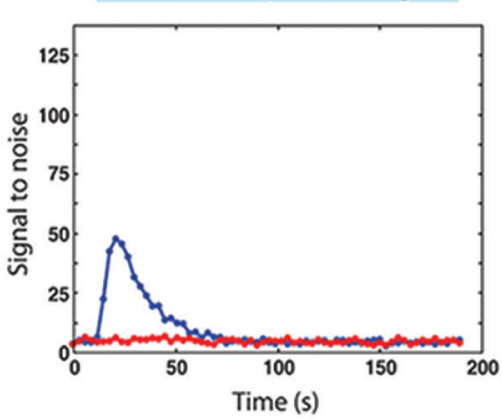

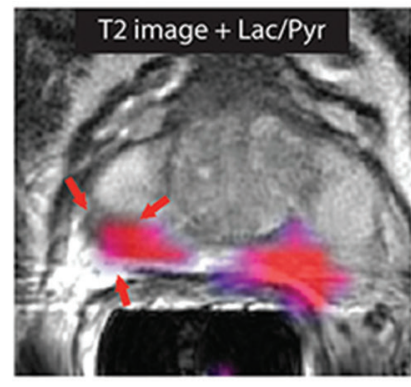

C
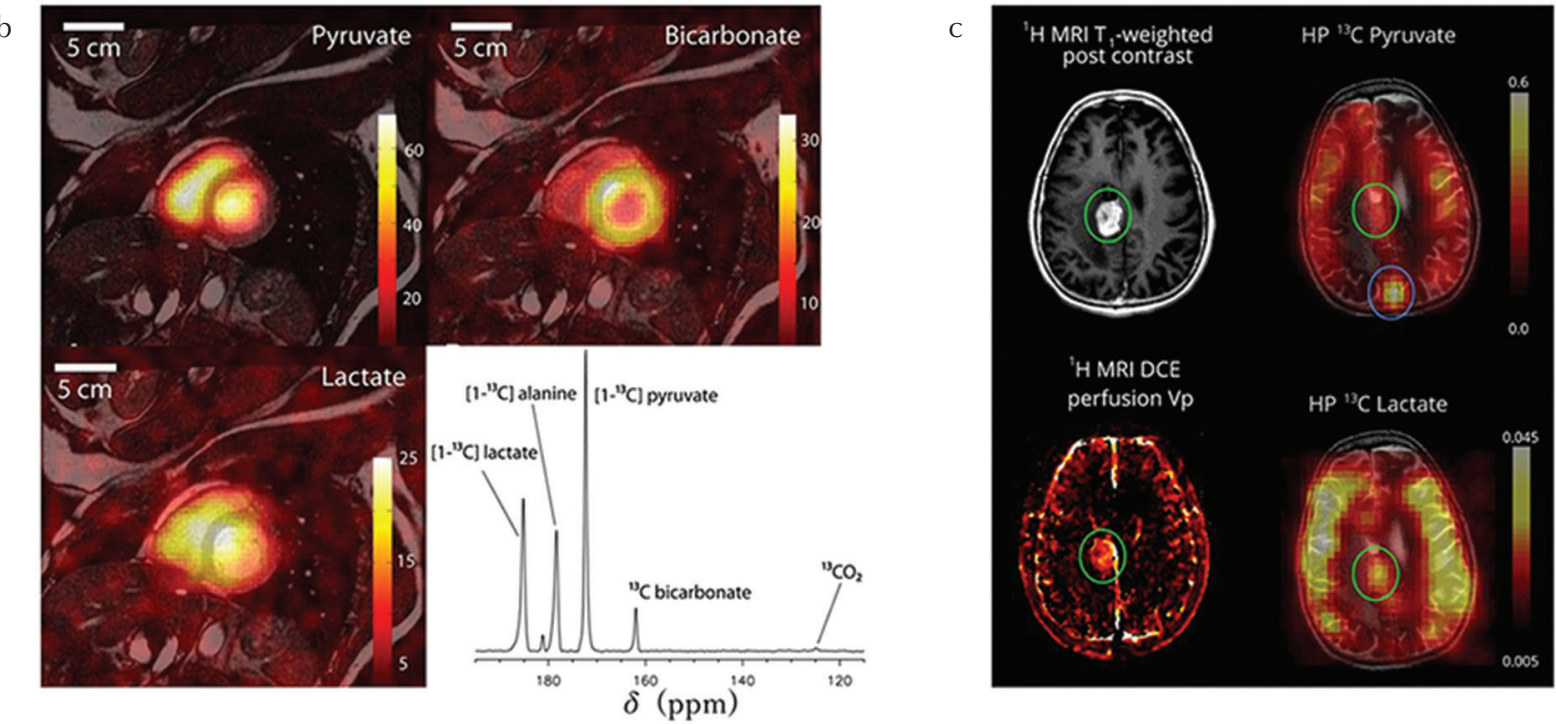

Fig. 4 Clinical examples of hyperpolarized $\left[1-{ }^{13} \mathrm{C}\right]$ pyruvate MRI. (a) Representative dynamic ${ }^{13} \mathrm{C}$ MRS data of pyruvate and lactate signal in prostate cancer region and contralateral prostate region of a prostate cancer patient, and lactate/pyruvate signal ratio map overlaid on a $\mathrm{T}_{2}$-weighted ${ }^{1} \mathrm{H}$ MR image (adapted from Figs. 2 and 4, respectively of Nelson et al. ${ }^{4}$ reprinted with permission from the American Association for the Advancement of Science (AAAS)). (b) HP $\left[1-{ }^{13} \mathrm{C}\right]$ pyruvate, lactate and bicarbonate MR images and a non-selective MR spectrum of the healthy human heart (adapted from Figs. 1 and 3, respectively of Cunningham et al. ${ }^{80}$ reprinted with permission from Wolters Klumer Health, Inc). (c) Comparison of HP $\left[1-{ }^{13} \mathrm{C}\right]$ pyruvate and lactate MR images to contrast-enhanced $\mathrm{T}_{1}$-weighted MRI and perfusion plasma volume mapping in a patient with recurrent glioblastoma (adapted from Fig. 4 of Miloushev et al. ${ }^{85}$ permission from the American Association for Cancer Research (AACR)). 
Table 1 Summary of ongoing clinical trials pertaining to hyperpolarized ${ }^{13} \mathrm{C}$ MRI (from clinicaltrials.gov, clinicaltrialsregister.eu and drks.de, accessed on 2019/06/12)

\begin{tabular}{|c|c|c|}
\hline $\begin{array}{l}\text { Primary condition } \\
\text { (number of trials) }\end{array}$ & Participating center (country) & Enrollment $^{\dagger}$ \\
\hline \multirow[t]{5}{*}{ Brain cancer ${ }^{6}$} & Sunnybrook Health Sciences Centre, Toronto (Canada) & 121 \\
\hline & UT Southwestern Medical Center, Dallas (USA) & 44 \\
\hline & M D Anderson Cancer Center, Dallas (USA) & 13 \\
\hline & University of California San Francisco, San Francisco (USA) & 80 \\
\hline & $\begin{array}{l}\text { UCSF Helen Diller Family Comprehensive Cancer Center, San } \\
\text { Francisco (USA) }\end{array}$ & 9 \\
\hline \multirow[t]{2}{*}{ Uterine and ovarian cancer ${ }^{2}$} & Sunnybrook Health Sciences Centre, Toronto (Canada) & 10 \\
\hline & Addenbrooke's Hospital, Cambridge (UK) & 40 \\
\hline \multirow[t]{2}{*}{ Breast cancer $^{2}$} & UT Southwestern - Advanced Imaging Research Center, Dallas (USA) & 110 \\
\hline & Sunnybrook Health Sciences Centre, Toronto (Canada) & 13 \\
\hline \multirow{2}{*}{$\begin{array}{l}\text { Traumatic brain injury and } \\
\text { CNS tumors }{ }^{2}\end{array}$} & UT Southwestern Medical Center, Dallas (USA) & 16 \\
\hline & Stanford University School of Medicine, Palo Alto (USA) & 10 \\
\hline Other: Sarcoma ${ }^{1}$ & Advanced Imaging Research Center, Dallas (USA) & 20 \\
\hline Fatty liver ${ }^{1}$ & UT Southwestern Medical Center, Dallas (USA) & 16 \\
\hline Pancreatic cancer $^{1}$ & Aarhus University Hospital, Aarhus (Denmark) & 15 \\
\hline Skin cancer ${ }^{1}$ & Aarhus University Hospital, Aarhus (Denmark) & 30 \\
\hline General cancer ${ }^{1}$ & Memorial Sloan Kettering Cancer Center, New York (USA) & 84 \\
\hline \multirow[t]{3}{*}{ Prostate cancer ${ }^{9}$} & University of California San Francisco, San Francisco (USA) & 261 \\
\hline & Sunnybrook Health Sciences Centre, Toronto (Canada) & 40 \\
\hline & M D Anderson Cancer Center, Dallas (USA) & 10 \\
\hline \multirow[t]{5}{*}{ Cardiovascular disease $^{5}$} & UT Southwestern Medical Center, Dallas (USA) & 10 \\
\hline & Sunnybrook Health Sciences Centre, Toronto (Canada) & 112 \\
\hline & University College London, London (UK) & 25 \\
\hline & University Hospital Zurich, Zurich (Switzerland) & 50 \\
\hline & Aarhus University Hospital, Aarhus (Denmark) & 20 \\
\hline
\end{tabular}

${ }^{\dagger}$ Enrollment: approximate patient numbers scanned or anticipated (in cases of multiple studies at the same center, enrollment represents a summation of the enrollment for each individual study).

Table 2 Non-exhaustive list of ${ }^{13} \mathrm{C}$ MR molecular probes polarizable by dynamic nuclear polarization (adapted with the publisher's permission from Table 1 of Hurd et al. ${ }^{163}$ ) and their chemical shift (and literature reference)

\begin{tabular}{|c|c|c|}
\hline $\mathrm{HP}{ }^{13} \mathrm{C}$ probe (chemical shift) & Metabolic products (chemical shift) & Biomedical applications \\
\hline$\left[1-^{13}\right.$ C]Pyruvate $(173 \mathrm{ppm})^{164}$ & $\begin{array}{l}{\left[1-{ }^{13} \mathrm{C}\right] \text { Lactate }(185 \mathrm{ppm}),\left[1-{ }^{13} \mathrm{C}\right] \text { alanine }(178 \mathrm{ppm}),} \\
{\left[1-{ }^{13} \mathrm{C}\right] \text { bicarbonate }(162 \mathrm{ppm}),\left[1-{ }^{13} \mathrm{C}\right] \text { pyruvate hydrate }} \\
(181 \mathrm{ppm}){ }^{164}\end{array}$ & Warburg effect (cancer) \\
\hline$\left[2-{ }^{13}\right.$ C]Pyruvate $(208 \mathrm{ppm})^{96}$ & $\begin{array}{l}{\left[2-{ }^{13} \mathrm{C}\right] \text { Lactate }(71 \mathrm{ppm}),{ }^{96}\left[2-{ }^{13} \mathrm{C}\right] \text { alanine }(53 \mathrm{ppm}),} \\
{\left[1-{ }^{13} \mathrm{C}\right] \text { citrate }(180-181 \mathrm{ppm}),{ }^{165}\left[5-{ }^{13} \mathrm{C}\right] \mathrm{glutamate}} \\
(184 \mathrm{ppm}),\left[1-{ }^{13} \mathrm{C}\right] \text { acetylcarnitine }(175 \mathrm{ppm}),\left[3-{ }^{13} \mathrm{C}\right] \\
\text { acetoacetate }(177 \mathrm{ppm}){ }^{96}\end{array}$ & $\begin{array}{l}\text { Tricarboxylic acid (TCA) } \\
\text { cycle metabolism }\end{array}$ \\
\hline${ }^{13} \mathrm{C}$-Urea $(162.5 \mathrm{ppm}){ }^{100}$ & None (end product) & Perfusion \\
\hline$\left[1,4-{ }^{13} \mathrm{C}_{2}\right]$ Fumarate $(175.4 \mathrm{ppm})^{103}$ & {$\left[1-{ }^{13} \mathrm{C}\right]$ Malate $(181.8 \mathrm{ppm}),\left[4-{ }^{13} \mathrm{C}\right]$ Malate $(180.6 \mathrm{ppm})^{103}$} & Cellular necrosis \\
\hline$\left[1-{ }^{13} \mathrm{C}\right]$ Dehydroascorbate $(174.0 \mathrm{ppm})^{109}$ & {$\left[1-{ }^{13} \mathrm{C}\right]$ Ascorbic acid (vitamin C) (177.8 ppm) ${ }^{109}$} & Redox status \\
\hline${ }^{13} \mathrm{C}$-Bicarbonate $(161 \mathrm{ppm}){ }^{113}$ & Carbon dioxide $(125 \mathrm{ppm})^{113}$ & $\mathrm{pH}$ mapping \\
\hline$\left[1,5-{ }^{13} \mathrm{C}_{2}\right]$ Zymonic acid $\left(\mathrm{ppm}_{\text {urea }}+10-15 \mathrm{ppm}\right)^{116^{*}}$ & None & \\
\hline$\left[5-{ }^{13} \mathrm{C}\right]$ Glutamine $(178.5 \mathrm{ppm})^{166}$ & {$\left[5-{ }^{13} \mathrm{C}\right]$ Glutamate $(181.5 \mathrm{ppm})^{166}$} & Glutaminase metabolism, \\
\hline$\left[1-{ }^{13} \mathrm{C}\right] \alpha$-ketoglutarate $(172.6 \mathrm{ppm})^{117}$ & {$\left[1-^{13} \mathrm{C}\right]$ Glutamate $(177.5 \mathrm{ppm})^{117}$} & TCA cycle metabolism \\
\hline$\left[1-{ }^{13} \mathrm{C}\right]$ Acetate $(182.5 \mathrm{ppm})^{120}$ & {$\left[1-{ }^{13} \mathrm{C}\right]$ Acetylcarnitine $(202.1 \mathrm{ppm})^{120}$} & $\begin{array}{l}\text { Acetyl-CoA synthetase } \\
\text { activity }\end{array}$ \\
\hline
\end{tabular}

"pH-dependent chemical shift. 
acetoacetate and acetylcarnitine production was observed post-injection of an anti-cancer agent in rats. ${ }^{96}$ The first clinical MR spectroscopy and imaging data of HP $\left[2-{ }^{13} \mathrm{C}\right]$ pyruvate in the healthy human brain was reported at the 2019 ISMRM meeting: ${ }^{97}$ however, application of the probe remains challenging due to the relatively low concentration of downstream metabolites generated; in one study, none were detectable. ${ }^{66}$

$\left[1-{ }^{13} \mathrm{C}\right]$ urea, the first hyperpolarized ${ }^{13} \mathrm{C}$ molecular MR imaging agent demonstrated by the d-DNP method, ${ }^{11}$ is metabolically inert and shows promise as a HP MRI agent for perfusion assessment. ${ }^{98,99}$ Furthermore, $\left[1-{ }^{13} \mathrm{C}\right]$ urea can be co-polarized with $\left[1-{ }^{13} \mathrm{C}\right]$ pyruvate for simultaneous assessment of metabolism and perfusion, ${ }^{100}$ and co-labeling with ${ }^{15} \mathrm{~N}_{2}$ exhibits prolonged ${ }^{13} \mathrm{C}$ relaxation times and improved $\mathrm{SNR}^{101}$ facilitating for example the investigation of renal functional changes. ${ }^{102}$

$\left[1,4-{ }^{13} \mathrm{C}_{2}\right]$ fumarate can be hyperpolarized by d-DNP and the rate of its conversion to malate, catalyzed by fumarase, is indicative of cellular necrosis. ${ }^{103} \mathrm{HP}\left[1,4-{ }^{13} \mathrm{C}_{2}\right]$ fumarate exhibits high sensitivity to necrosis in myocardial infarction $^{104}$ and acute kidney injury ${ }^{105}$ among other tissue pathologies, is complementary to $\left[1-{ }^{13} \mathrm{C}\right]$ pyruvate in the assessment of treatment response (Fig. 5a) in breast cancer ${ }^{106}$ and efficient co-polarization schemes offer simultaneous probing of multiple metabolic pathways. ${ }^{107}$

Hyperpolarization of the reduced and oxidized forms of vitamin $\mathrm{C}$-namely $\left[1-{ }^{13} \mathrm{C}\right]$ dehydroascorbate and $\left[1-{ }^{13} \mathrm{C}\right]$ ascorbate, respectively - offers a novel means to probe intracellular redox status, a critical factor in normal and abnormal cellular function. ${ }^{108,109}$ High concentrations of $\left[1-{ }^{13} \mathrm{C}\right]$ ascorbate can be observed post-injection of $\left[1-{ }^{13} \mathrm{C}\right]$ dehydroascorbate, and reduced HP $\left[1-{ }^{13} \mathrm{C}\right]$ ascorbate signal has been utilized as an MR biomarker of renal oxidative stress. ${ }^{110,111}$

Several HP ${ }^{13} \mathrm{C}$-based molecular probes have been proposed for measurement of $\mathrm{pH},{ }^{112}$ a critical physiological factor. In particular, injection of hyperpolarized ${ }^{13} \mathrm{C}$-bicarbonate and monitoring of its conversion to ${ }^{13} \mathrm{CO}_{2}$ has been proposed to monitor $\mathrm{pH}^{113}$ and demonstrates sensitivity to abnormal $\mathrm{pH}$ in cancer ${ }^{113}$ and ischemic heart disease. ${ }^{114}$ An alternative method involves monitoring the $\mathrm{HP}{ }^{13} \mathrm{CO}_{2}$ production from injected $\left[1-{ }^{13} \mathrm{C}\right]$ pyruvate. ${ }^{115}$ Recently, HP $\left[1,5-{ }^{13} \mathrm{C}_{2}\right]$ zymonic acid has been proposed for high-sensitivity in vivo $\mathrm{pH}$ mapping, exhibiting a $\mathrm{pH}$-sensitive chemical shift and $\mathrm{T}_{1}$ benefits over $\left[1-{ }^{13} \mathrm{C}\right]$ bicarbonate. ${ }^{116}$

To probe glutaminase and alanine transaminase metabolism, respectively, HP $\left[5-{ }^{13} \mathrm{C}\right]$ glutamine and $\left[1-{ }^{13} \mathrm{C}\right]$ glutamate have been investigated. Conversion of injected HP $\left[1-{ }^{13} \mathrm{C}\right] \alpha$-ketoglutarate to $\left[1-{ }^{13} \mathrm{C}\right]$ glutamate has been proposed as a potential biomarker of isocitrate dehydrogenase 1 gene mutations in glioma. ${ }^{117}$ Although the longitudinal relaxation of ${ }^{13} \mathrm{C}$ nuclear spins in the glucose molecule is extremely short, perdeuteration has facilitated studies of glycolysis using HP $\left[\mathrm{U}-{ }^{13} \mathrm{C}\right]$ glucose in cells ${ }^{118}$ and in vivo. ${ }^{119}$ The action of acetyl-CoA synthetase in generating acetyl-CoA-a crucial molecule in fatty acid synthesis and TCA cycle metabolism - has been investigated with HP $\left[1-{ }^{13} \mathrm{C}\right]$ acetate in the heart ${ }^{120,121}$ and skeletal muscle. ${ }^{122}$

\section{PHIP: candidate ${ }^{13} \mathrm{C}$ molecular and metabolic MRI probes}

The choice of molecular probes for conventional hydrogenative PHIP is fundamentally limited by the requirement of an unsaturated precursor substrate (i.e. a molecule containing a double or triple bond to which parahydrogen is added to yield the hyperpolarized probe). ${ }^{123}$ Nevertheless, a number of promising $\mathrm{HP}{ }^{13} \mathrm{C}$ probes for biomedical MR applications can be produced with a polarization level comparable to or approaching that of d-DNP. Some of these are highlighted in the following text and also in Table 3; for an exhaustive list, we refer the reader to Hövener et al. ${ }^{41}$.

To date some of the most promising probes for metabolic MRI by PHIP are based on succinate and its derivatives (Fig. 6), the metabolic activity of which was introduced earlier. Hyperpolarized $\left[1-{ }^{13} \mathrm{C}\right]$ succinate can be generated by one of two PHIP strategies: two-step parahydrogen addition, first to $\left[1-{ }^{13} \mathrm{C}\right]$ acetylenedicarboxylate $(\mathrm{ADC})$ to yield $\left[1-{ }^{13} \mathrm{C}\right]$ maleate, to which parahydrogen is added again to yield $\left[1-{ }^{13} \mathrm{C}\right]$ succinate ${ }^{124}$; or by single-step parahydrogen addition to $\left[1-{ }^{13} \mathrm{C}\right]$ fumarate. ${ }^{125,126}$ The latter method offers a prolonged $\left[1-{ }^{13} \mathrm{C}\right]$ succinate polarization lifetime, particularly if deuterated fumarate is used, and also reduces the risk of undesired injection of ADC, which is mildly toxic, and also the intermediate (maleate). ${ }^{125}$ Whilst initial in vivo experiments in the rat brain did not exhibit clear metabolic conversion of PHIP-polarized $\left[1-{ }^{13} \mathrm{C}\right]$ succinate, ${ }^{124}$ the second hydrogenation approach enabled detection of downstream TCA cycle metabolites in a murine tumor model. ${ }^{126}$ Furthermore, the diethyl ester of $\left[1-{ }^{13} \mathrm{C}\right]$ succinate, derived by parahydrogen addition of diethyl $\left[1-{ }^{13} \mathrm{C}\right]$ fumarate, appears to exhibit some TCA cycle metabolic sensitivity and was shown to distinguish murine tumor characteristics. ${ }^{126,127}$

Hyperpolarized hydroxyethyl $\left[1-{ }^{13} \mathrm{C}\right]$ propionate, produced by parahydrogen addition of hydroxyethyl $\left[1-{ }^{13} \mathrm{C}\right]$ acrylate (HEA), presents a potential high-sensitivity PHIP contrast agent for angiography applications. ${ }^{50,128,129}$ In a recent study, the entire process of parahydrogen addition to HEA followed by polarization transfer, injection and in vivo MRI detection of HEP was realized within an MRI system, i.e. without the requirement of an external polarizer. ${ }^{130}$ Since 2-hydroxyethyl[1${ }^{13} \mathrm{C}$ ]propionate is easily polarized by PHIP and has strong, welldefined heteronuclear spin-spin couplings, it has also been utilized to validate several novel techniques for optimization of polarization transfer between parahydrogen and ${ }^{13} \mathrm{C} .{ }^{50,131,132}$

Hyperpolarized tetrafluoropropyl $\left[1-{ }^{13} \mathrm{C}\right]$ propionate (TFPP) can be derived parahydrogen addition of the corresponding acrylate precursor and subsequent polarization transfer, and has been proposed as a "targeted" molecular agent for interrogating lipid-rich atherosclerotic plaques. ${ }^{133}$ However, whilst $\mathrm{HP}{ }^{13} \mathrm{C}$-HEP and ${ }^{13} \mathrm{C}$-succinate can be generated in the 

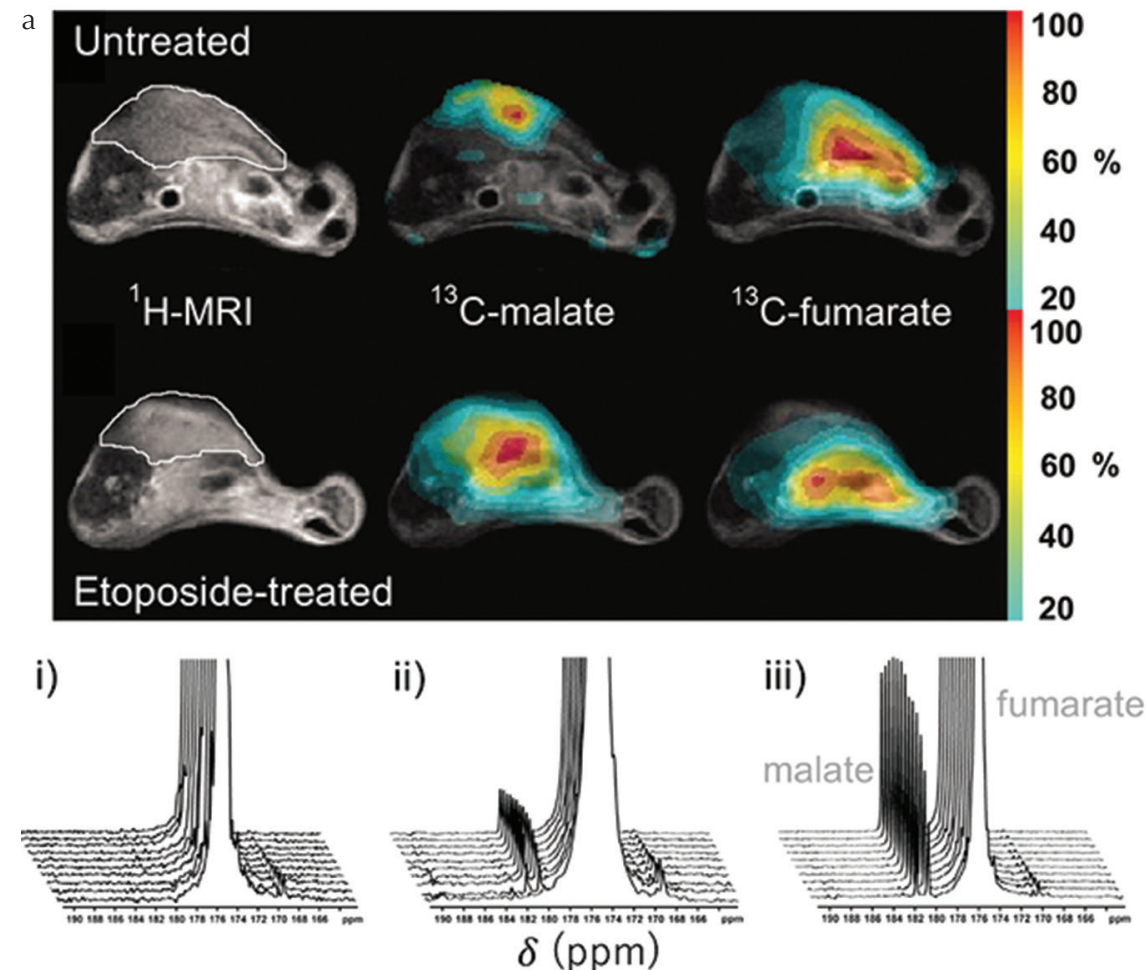

b
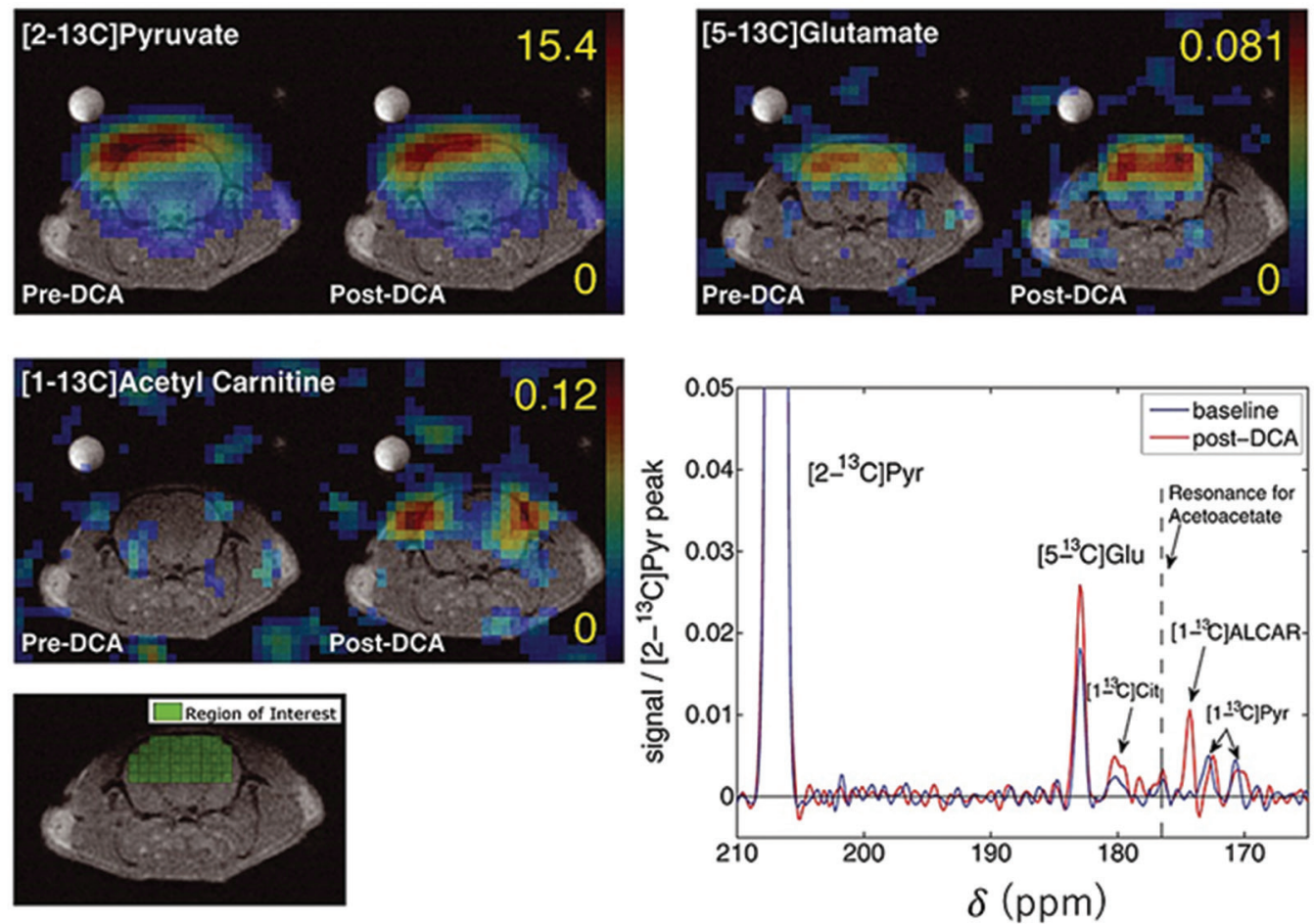

Fig. 5 Pre-clinical MRI examples of promising HP ${ }^{13} \mathrm{C}$ probes other than $\left[1-{ }^{13} \mathrm{C}\right]$ pyruvate. $(\mathbf{a}) \mathrm{HP}{ }^{13} \mathrm{C}$ chemical shift imaging $(\mathrm{CSI})$ of cellular necrosis pre- and post-etoposide treatment (increased necrosis) in a murine tumor model after $\mathrm{HP}\left[1,4-{ }^{13} \mathrm{C}_{2}\right]$ fumarate injection, and ${ }^{13} \mathrm{C}$ MR spectra obtained from murine lymphoma cells; (i) untreated, (ii) post-etoposide treatment, (iii) lysed cells, demonstrating a strong relationship between malate production and necrosis (adapted from Figs. 1 and 4 of Gallagher et al. ${ }^{103}$ with the publisher's permission). (b) CSI-derived maps and accompanying spectra of metabolites derived from mitochondrial metabolism after injection of $\left[2-{ }^{13} \mathrm{C}\right]$ pyruvate into a healthy rat, exhibiting $\left[1-{ }^{13} \mathrm{C}\right]$ acetyl carnitine and tricarboxylic acid (TCA) cycle-derived $\left[5-{ }^{13} \mathrm{C}\right]$ glutamate resonances (adapted with the publisher's permission from Park et al. ${ }^{167}$ ). Results obtained pre- and post-injection of dichloroacetate (DCA), a proposed anti-cancer drug used to influence acetyl-CoA production by modulating pyruvate dehydrogenase, are shown. 
Table 3 Non-exhaustive list of ${ }^{13} \mathrm{C}$ MR molecular probes polarizable by parahydrogen-induced polarization (adapted with the publisher's permission from Table 1 of Hövener et al. ${ }^{41}$ and their chemical shift (and literature reference ${ }^{\dagger}$ )

\begin{tabular}{|c|c|c|}
\hline $\mathrm{HP}^{13} \mathrm{C}$ precursor & Hydrogenation products & Biomedical applications \\
\hline$\left[1{ }^{13} \mathrm{C}\right]$ Fumarate $(166.5 \mathrm{ppm})^{155}$ & {$\left[1-{ }^{13} \mathrm{C}\right]$ Succinate $(175 \mathrm{ppm})^{124}$} & $\begin{array}{l}\text { Tricarboxylic acid (TCA) } \\
\text { cycle metabolism }\end{array}$ \\
\hline Diethyl $\left[1-{ }^{13} \mathrm{C}\right]$ fumarate $(167.4 \mathrm{ppm})^{127}$ & Diethyl $\left[1-{ }^{13} \mathrm{C}\right]$ succinate $(175.8 \mathrm{ppm})^{127}$ & TCA cycle metabolism \\
\hline${ }^{13} \mathrm{C}-$ Hydroxyethyl-acrylate & ${ }^{13} \mathrm{C}-\mathrm{Hydroxyethylpropionate}(\sim 180 \mathrm{ppm})^{50}$ & Angiography \\
\hline Tetrafluoropropyl $\left[1-{ }^{13} \mathrm{C}\right]$ acrylate & Tetrafluoropropyl[1-13 C]propionate (174 and $177 \mathrm{ppm})^{133}$ & Atheromatous plaques \\
\hline $\begin{array}{l}\text { Propargyl }\left[1-{ }^{13} \mathrm{C}\right] \text { pyruvate } \\
(160 \mathrm{ppm})^{60}\end{array}$ & $\begin{array}{l}\text { Allyl }\left[1-{ }^{13} \mathrm{C}\right] \text { pyruvate }(160.5 \mathrm{ppm})^{60} \rightarrow\left[1-{ }^{13} \mathrm{C}\right] \text { pyruvate } \\
(173 \mathrm{ppm}) \text { after hydrolysis }\end{array}$ & Warburg effect (cancer) \\
\hline $\begin{array}{l}\text { Vinyl }\left[1-{ }^{13} \mathrm{C}\right] \text { acetate } \\
(168 \mathrm{ppm})^{60}\end{array}$ & $\begin{array}{l}\text { Ethyl }\left[1-{ }^{13} \mathrm{C}\right] \text { acetate }(174 \mathrm{ppm}){ }^{147} \rightarrow\left[1-{ }^{13} \mathrm{C}\right] \text { acetate } \\
(182.5 \mathrm{ppm}) \text { after hydrolysis }\end{array}$ & $\begin{array}{l}\text { Acetyl-CoA synthetase } \\
\text { activity }\end{array}$ \\
\hline
\end{tabular}

${ }^{+}$Chemical shift values only quoted for the particular solvent in the literature reference cited.

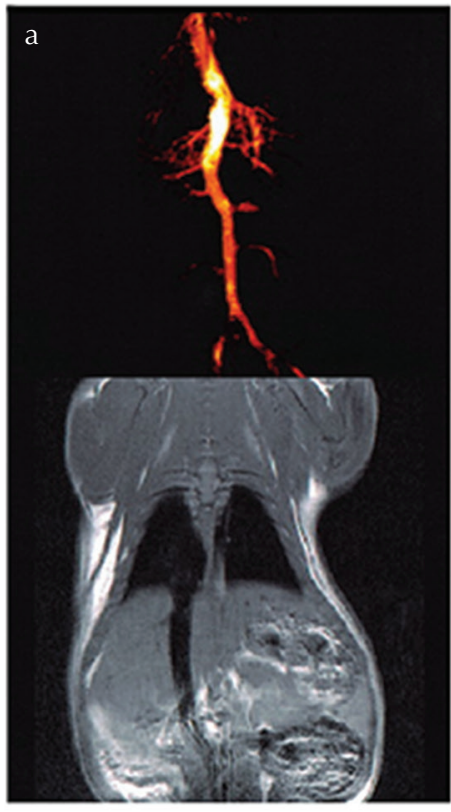

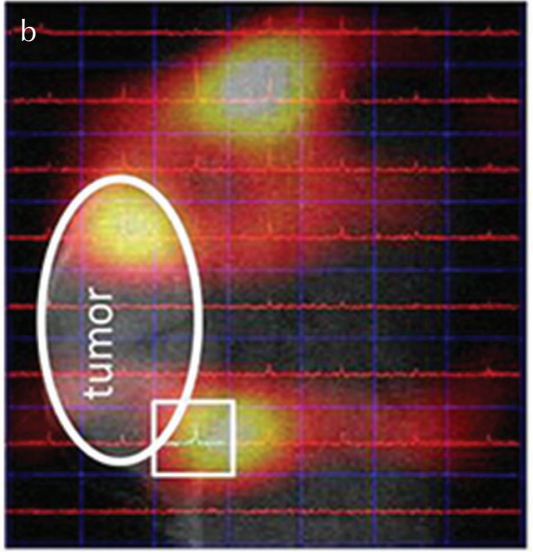

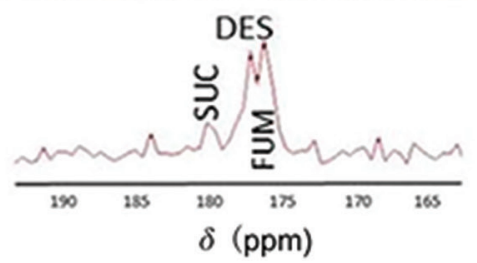

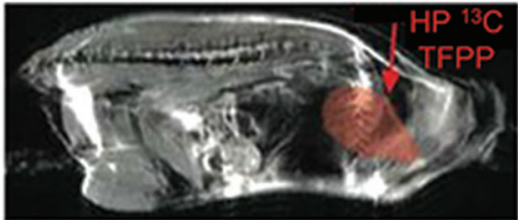
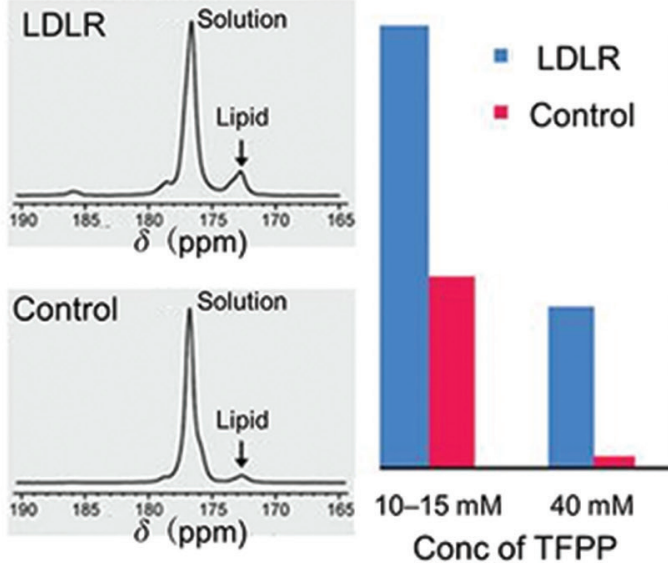

Fig. 6 In vivo magnetic resonance imaging (MRI) application of several hyperpolarized ${ }^{13} \mathrm{C}$ probes generated by parahydrogen-induced polarization (PHIP). (a) MRI angiogram of $\mathrm{HP}{ }^{13} \mathrm{C}$-labeled malate dimethyl ester with corresponding ${ }^{1} \mathrm{H}$ spin echo reference image of a healthy rat (adapted with permission from Golman et al ${ }^{49}$ ). (b) Chemical shift imaging $(\mathrm{CSI})$ of HP diethyl $\left[1-{ }^{13} \mathrm{C}\right]$ succinate in a murine model of renal cell carcinoma (reproduced from Zacharias et al. ${ }^{126}$ under the Creative Commons Attribution License). The ${ }^{13} \mathrm{C}$ spectrum corresponding to the pixel indicated by the white square shows tricarboxylic acid (TCA) cycle metabolism of diethyl succinate (DES) to succinate (SUC) and fumarate (FUM). (c) Representative HP tetrafluoropropyl $\left[1-{ }^{13} \mathrm{C}\right]$ propionate (TFPP) fast imaging with steady-state precession (FISP) image overlaid on a ${ }^{1} \mathrm{H}$ RARE image, and HP ${ }^{13} \mathrm{C}-\mathrm{TFPP}$ spectra obtained from low density lipoprotein receptor (LDLR) deficient mice compared with control mice, demonstrating excess lipid in LDLR mice (reproduced from Bhattacharya et al. ${ }^{133}$ with the publisher's permission).

pure aqueous phase using a water-soluble catalyst, TFPP requires a high dose of ethanol as a co-solvent, limiting potential in vivo applications. ${ }^{133}$

Since $\left[1-{ }^{13} \mathrm{C}\right]$ ethyl pyruvate ester has been shown to be polarizable by d-DNP and shows some promise in comparison to $\left[1-{ }^{13} \mathrm{C}\right]$ pyruvate for functional brain imaging applications, ${ }^{134}$ the hydrogenation precursor $\left[1-{ }^{13} \mathrm{C}\right]$ vinyl pyruvate is an interesting potential target for PHIP, however an efficient synthesis route remains elusive. ${ }^{60}$

Shchepin et al. ${ }^{135}$ have proposed $\left[1-{ }^{13} \mathrm{C}\right]$ phospholactate, the hydrogenation product of $\left[1-{ }^{13} \mathrm{C}\right]$ phosphoenolpyruvate, as a possible route to HP $\left[1-{ }^{13} \mathrm{C}\right]$ lactate in vivo, which 
is subsequently taken up by tumors and several critical organs. ${ }^{59,136}$ The hydrogenation reaction can relatively easily be performed in water, ${ }^{137}$ which holds promise for future biomedical studies.

Ester derivatives of ${ }^{13} \mathrm{C}$-glucose have been demonstrated to be polarizable by PHIP; ${ }^{138}$ however, the short polarization lifetime $(\sim s)$ must be overcome (e.g. by deuteration) to facilitate the realization of in vivo glycolysis measurement by PHIP of glucose derivatives and the possibility of corroboration against FDG-PET.

Alteration of choline metabolism is a hallmark of tumor progression, and several groups have investigated choline precursors as potential molecular probes for PHIP. ${ }^{139,140}$ Rather than ${ }^{13} \mathrm{C},{ }^{15} \mathrm{~N}$-labeling can be used; although ${ }^{15} \mathrm{~N}$ possesses an intrinsically low gyromagnetic ratio and hence sensitivity compared with ${ }^{13} \mathrm{C}$, extremely long relaxation times can be realized, enabling metabolism dynamics to be followed over the course of several minutes. In particular, the recent demonstration of $12 \%{ }^{15} \mathrm{~N}$ polarization with a lifetime of over $20 \mathrm{~min}$ on a choline derivative is of interest for in vivo cancer metabolism applications. ${ }^{141}$

\section{Side-arm hydrogenation (PHIP-SAH): a route to $\mathrm{HP}\left[1-{ }^{13} \mathrm{C}\right]$ pyruvate}

The majority of the above-mentioned probes offer only limited or no metabolic information of sufficient sensitivity compared with $\left[1-{ }^{13} \mathrm{C}\right]$ pyruvate produced by d-DNP; however, the lack of a suitable hydrogenation precursor of pyruvate, lactate or other metabolically-linked molecules has led Reineri et al. ${ }^{142}$ to develop the method of side-arm hydrogenation PHIP (PHIP$\mathrm{SAH})$. In PHIP-SAH, parahydrogen is added to an unsaturated ester of the molecule of choice in the organic phase, where the hydrogenation reaction is most efficient, then polarization is transferred from ${ }^{1} \mathrm{H}$ to the $\left[1-{ }^{13} \mathrm{C}\right]$ atom of the carboxylic acid of interest, and finally the ester "side-arm" is hydrolytically cleaved to yield the HP carboxylic acid of interest along with ester alcohol in the aqueous phase. Hyperpolarized $\left[1-{ }^{13} \mathrm{C}\right]$ pyruvate, $\left[1-{ }^{13} \mathrm{C}\right]$ acetate ${ }^{142}$ and $\left[1-{ }^{13} \mathrm{C}\right]$ lactate ${ }^{143}$ have been demonstrated using this approach.

Following optimization of the initial experimental procedure with a view to in vivo application, ${ }^{144} \mathrm{a}{ }^{13} \mathrm{C}$ polarization of $\sim 5 \%$ on $\left[1-{ }^{13} \mathrm{C}\right]$ pyruvate at the time of experiment was obtained, enabling realization of the first in vivo metabolic MR spectroscopy and imaging in a mouse model of dilated cardiomyopathy, ${ }^{145}$ the results of which are highlighted in Fig. 7. Whilst the sensitivity remains relatively low compared with that produced by d-DNP, a recent comparison of the polarization efficiency of several pyruvate and acetate precursors has provided insights into the best substrate of choice for future in vivo metabolic MRI applications. ${ }^{146}$ In particular, hydrogenation products ethyl acetate and allyl pyruvate (hydrogenation products of vinyl acetate and propargyl pyruvate, respectively) were found to yield the highest ${ }^{13} \mathrm{C}$ polarization. ${ }^{146}$ Furthermore, when a deuterated

a
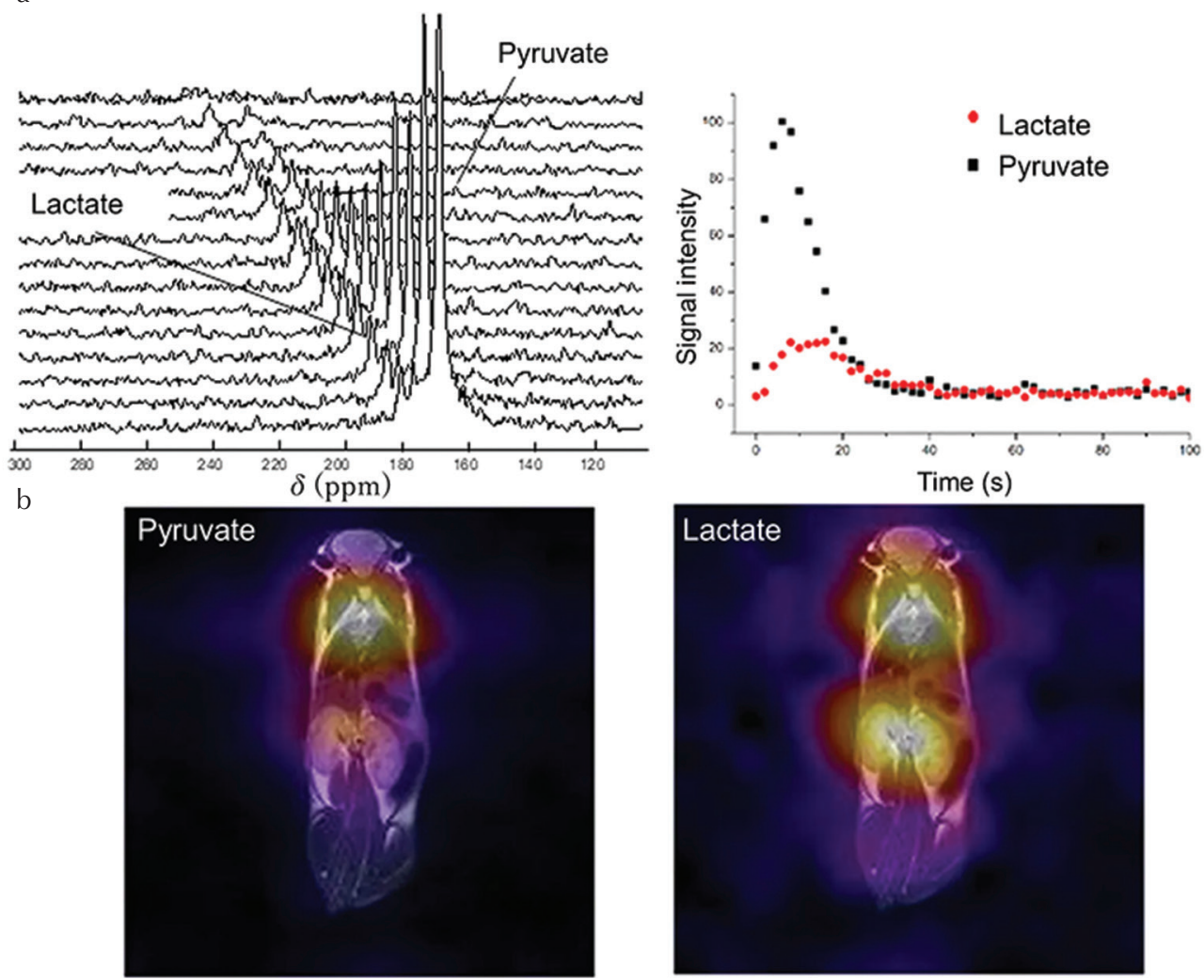

Fig. 7 (a) Slice-selective dynamic ${ }^{13} \mathrm{C}$ MRS of a healthy wild-type mouse after injection of HP $\left[1-{ }^{13} \mathrm{C}\right]$ pyruvate produced by parahydrogen-induced polarization (PHIP)-side-arm hydrogenation $(\mathrm{SAH})$, and (b) corresponding whole-body ${ }^{13} \mathrm{C}$ chemical shift imaging (CSI) of $\left[1-{ }^{13} \mathrm{C}\right]$ pyruvate and $\left[1-{ }^{13} \mathrm{C}\right]$ lactate (reproduced from Figs. 2 and 3 of Cavallari et al. $^{145}$ under the Creative Commons CCBY License). 
precursor is combined with optimized polarization transfer techniques, ${ }^{13} \mathrm{C}$ polarization of more than $50 \%$ on acetate has been realized using the vinyl ester precursor, ${ }^{147}$ which may permit in vivo investigations of acetyl-CoA synthetase activity in the near future by PHIP.

\section{Future Perspectives}

Ongoing and future clinical trials of $\left[1{ }^{13} \mathrm{C}\right]$ pyruvate MRI serve a critical role in evaluating the clinical viability of the technique for and beyond oncological studies of metabolism, and also in assessing the reproducibility and robustness of hyperpolarized MR acquisition methods and analysis procedures in order to provide guidelines to standardize workflow for future multi-site validation studies. ${ }^{5}$ In particular, robust clinical comparison studies of HP $\left[1-{ }^{13} \mathrm{C}\right]$ pyruvate MRI and ${ }^{18} \mathrm{~F}-\mathrm{FDG}$-PET in several oncological pathologies are required to further understanding of the relationship between the pathophysiological information gleaned from each technique and further accelerate clinical translation. ${ }^{89,90}$ Clinical trials of d-DNP probes such as $\left[1-{ }^{13} \mathrm{C}\right]$ fumarate, $\left[1-{ }^{13} \mathrm{C}\right]$ bicarbonate and others are either pending or expected in the near future, and co-polarization techniques are likely to yield unprecedented access to multiple aspects of metabolic function with a single hyperpolarized dose. ${ }^{107,148} \mathrm{~d}$-DNP probe development has not ceased with the advent of clinical application of $\left[1-{ }^{13} \mathrm{C}\right]$ pyruvate, with several novel probes reported in the last few years. ${ }^{149,151}$ In parallel to clinical studies, the fundamental science of d-DNP remains a field of active development. ${ }^{152}$

Whilst biomedical applications of PHIP are relatively few in number to date when compared with those of d-DNP, novel approaches such as PHIP-SAH offer an expanded palette of polarizable molecular targets and a low-cost means of generating HP $\left[1-{ }^{13} \mathrm{C}\right]$ pyruvate for preclinical and with further refinement, eventually clinical applications. ${ }^{142,145}$ In addition, the development of increasingly efficient and versatile hydrogenation catalysts is a thriving research field (see e.g. Glöggler et al., ${ }^{153}$ Leutzsch et al. ${ }^{154}$ ). In particular, rhodium-based catalysts commonly used for efficient hydrogenation predominantly yield cis-selective products, but a novel trans-selective ruthenium-based catalyst has recently been shown to demonstrate hyperpolarized $\left[1-{ }^{13} \mathrm{C}\right]$ fumarate by parahydrogen addition to acetylene $\left[1-{ }^{13} \mathrm{C}\right]$ dicarboxylate for the first time. ${ }^{155}$ With appropriate filtering of the catalyst ${ }^{156}$ and other unwanted co-solvents or hydrolysis side products (in the case of PHIP-SAH), the purity of injected doses can be improved to appropriately high levels with a view to clinical application in the foreseeable future.

It is not only the ${ }^{13} \mathrm{C}$ nucleus that shows promise for biomedical hyperpolarized MRI applications; as previously noted, the ${ }^{15} \mathrm{~N}$ nucleus has a relatively low MR sensitivity, but exhibits extremely long polarization lifetimes and metabolic probes can be prepared in an environment suitable for biological application, analogous to ${ }^{13} \mathrm{C} .{ }^{157,158} \mathrm{In}$ addition, ${ }^{19} \mathrm{~F}$, which has a gyromagnetic ratio and therefore a baseline sensitivity similar to that of the proton, may find biomedical application in targeted MRI of hyperpolarized ${ }^{19} \mathrm{~F}$-labelled drugs, though limited progress in this direction has been made to date. ${ }^{159}$ Furthermore, while all the above noted applications pertain to liquid-phase molecular probes, parahydrogen can be used in combination with a solid-phase catalyst to generate ${ }^{1} \mathrm{H}$-hyperpolarized propane (from propylene) in the gaseous phase. ${ }^{160,161}$ which shows some promise as a relatively cheap alternative to hyperpolarized noble gases for biomedical lung imaging, though the high ${ }^{1} \mathrm{H}$ background signal may be problematic and no in vivo experiments have been attempted to date.

Finally, the SABRE parahydrogen method, wherein polarization transfer occurs by reversible exchange and the target molecule remains chemically unaltered upon interaction with parahydrogen, has the potential yield heteronuclear $\left({ }^{13} \mathrm{C},{ }^{15} \mathrm{~N}\right)$ hyperpolarization on a broader range of molecular imaging probes than conventional PHIP and may lead to several unprecedented avenues of biomedical application. ${ }^{162}$ Although to date no in vivo experiments have been performed with SABRE-polarized probes, the recent demonstration of both hyperpolarized $\left[1-{ }^{13} \mathrm{C}\right]$ and $\left[2-{ }^{13} \mathrm{C}\right]$ pyruvate, ${ }^{14}$ although at relatively low polarizations, represents a significant step toward biomedical application.

\section{Acknowledgments}

NJS is an international research fellow of the Japanese Society for the Promotion of Science (JSPS).

\section{Conflicts of Interest}

The authors declare that they have no conflicts of interest.

\section{References}

1. Nikolaou P, Goodson BM, Chekmenev EY. NMR hyperpolarization techniques for biomedicine. Chemistry 2015; 21:3156-3166.

2. Liu Z, Araki T, Okajima Y, Albert M, Hatabu H. Pulmonary hyperpolarized noble gas MRI: recent advances and perspectives in clinical application. Eur J Radiol 2014; 83:1282-1291.

3. Kovtunov KV, Pokochueva EV, Salnikov OG, et al. Hyperpolarized NMR spectroscopy: d-DNP, PHIP, and SABRE techniques. Chem Asian J 2018; 13:1857-1871.

4. Nelson SJ, Kurhanewicz J, Vigneron DB, et al. Metabolic imaging of patients with prostate cancer using hyperpolarized $\left[1-{ }^{13} \mathrm{C}\right]$ pyruvate. Sci Transl Med 2013; 5:198ra108.

5. Kurhanewicz J, Vigneron DB, Ardenkjaer-Larsen JH, et al. Hyperpolarized ${ }^{13} \mathrm{C}$ MRI: path to clinical translation in oncology. Neoplasia 2019; 21:1-16.

6. Ardenkjaer-Larsen JH, Leach AM, Clarke N, Urbahn J, Anderson D, Skloss TW. Dynamic nuclear polarization polarizer for sterile use intent. NMR Biomed 2011; 24:927-932. 
7. Hirsch ML, Kalechofsky N, Belzer A, Rosay M, Kempf JG. Brute-force hyperpolarization for NMR and MRI. J Am Chem Soc 2015; 137:8428-8434.

8. Krjukov EV, O'Neill JD, Owers-Bradley JR. Brute force polarization of ${ }^{129} \mathrm{Xe}$. J Low Temp Phys 2005; 140:397-408.

9. Walker TG, Happer W. Spin-exchange optical pumping of noble-gas nuclei. Rev Mod Phys 1997; 69:629-642.

10. Colegrove FD, Schearer LD, Walters GK. Polarization of $\mathrm{He}^{3}$ gas by optical pumping. Phys Rev 1963; 132:2561-2572.

11. Ardenkjaer-Larsen JH, Fridlund B, Gram A, et al. Increase in signal-to-noise ratio of $>10,000$ times in liquid-state NMR. Proc Natl Acad Sci U S A 2003; 100:10158-10163.

12. Bowers CR, Weitekamp DP. Parahydrogen and synthesis allow dramatically enhanced nuclear alignment. J Am Chem Soc 1987; 109:5541-5542.

13. Adams RW, Aguilar JA, Atkinson KD, et al. Reversible interactions with para-hydrogen enhance NMR sensitivity by polarization transfer. Science 2009;323:1708-1711.

14. Iali W, Roy SS, Tickner BJ, Ahwal F, Kennerley AJ, Duckett SB. Hyperpolarizing pyruvate through signal amplification by reversible exchange (SABRE). Angew Chem Int Ed Engl 2019; 58:10271-10275.

15. Robertson TBR, Mewis RE. Perspective on the hyperpolarisation technique signal amplification by reversible exchange (SABRE) in NMR spectroscopy and MR imaging. Annu Rep NMR Spectrosc 2018; 93:145-212.

16. Zhao L, Mulkern R, Tseng $\mathrm{CH}$, et al. Gradient-echo imaging considerations for hyperpolarized 129Xe MR. J Magn Reson B 1996; 113:179-183.

17. Hövener JB, Knecht S, Schwaderlapp N, Hennig J, von Elverfeldt D. Continuous re-hyperpolarization of nuclear spins using parahydrogen: theory and experiment. Chemphyschem. 2014; 15:2451-2457.

18. Carravetta M, Levitt MH. Long-lived nuclear spin states in high-field solution NMR. J Am Chem Soc 2004; 126: 6228-6229.

19. Nagashima K. Optimum pulse flip angles for multi-scan acquisition of hyperpolarized NMR and MRI. J Magn Reson 2008; 190:183-188.

20. Wang J, Wright AJ, Hu DE, Hesketh R, Brindle KM. Single shot three-dimensional pulse sequence for hyperpolarized ${ }^{13}$ C MRI. Magn Reson Med 2017; 77:740-752.

21. Gordon JW, Hansen RB, Shin PJ, Feng Y, Vigneron DB, Larson PEZ. 3D hyperpolarized C-13 EPI with calibrationless parallel imaging. J Magn Reson 2018; 289:92-99.

22. Hu S, Lustig M, Chen AP, et al. Compressed sensing for resolution enhancement of hyperpolarized 13C flyback 3D-MRSI. J Magn Reson 2008; 192:258-264.

23. Schroeder MA, Atherton HJ, Ball DR, et al. Real-time assessment of Krebs cycle metabolism using hyperpolarized ${ }^{13} \mathrm{C}$ magnetic resonance spectroscopy. FASEB J 2009; 23:2529-2538.

24. Durst M, Koellisch U, Frank A, et al. Comparison of acquisition schemes for hyperpolarised ${ }^{13} \mathrm{C}$ imaging. NMR Biomed 2015; 28:715-725.

25. Golman K, Petersson JS, Magnusson P, et al. Cardiac metabolism measured noninvasively by hyperpolarized 13C MRI. Magn Reson Med 2008; 59:1005-1013.
26. Yen YF, Kohler SJ, Chen AP, et al. Imaging considerations for in vivo ${ }^{13} \mathrm{C}$ metabolic mapping using hyperpolarized ${ }^{13}$ C-pyruvate. Magn Reson Med 2009; 62:1-10.

27. Larson PE, Bok R, Kerr AB, et al. Investigation of tumor hyperpolarized $\left[1-{ }^{13} \mathrm{C}\right]$-pyruvate dynamics using timeresolved multiband RF excitation echo-planar MRSI. Magn Reson Med 2010; 63:582-591.

28. Mayer D, Yen YF, Tropp J, Pfefferbaum A, Hurd RE, Spielman DM. Application of subsecond spiral chemical shift imaging to real-time multislice metabolic imaging of the rat in vivo after injection of hyperpolarized 13C1pyruvate. Magn Reson Med 2009; 62:557-564.

29. Wiesinger F, Weidl E, Menzel MI, et al. IDEAL spiral CSI for dynamic metabolic MR imaging of hyperpolarized [1-13C]pyruvate. Magn Reson Med 2012; 68:8-16.

30. Reeder SB, Brittain JH, Grist TM, Yen YF. Least-squares chemical shift separation for (13)C metabolic imaging. J Magn Reson Imaging 2007; 26:1145-1152.

31. Schulte RF, Sperl JI, Weidl E, et al. Saturation-recovery metabolic-exchange rate imaging with hyperpolarized [1-13C] pyruvate using spectral-spatial excitation. Magn Reson Med 2013; 69:1209-1216.

32. Leupold J, Månsson S, Petersson JS, Hennig J, Wieben O. Fast multiecho balanced SSFP metabolite mapping of (1) $\mathrm{H}$ and hyperpolarized (13)C compounds. MAGMA 2009; 22:251-256.

33. Hansen ES, Stewart NJ, Wild JM, Stødkilde-Jørgensen $\mathrm{H}$, Laustsen C. Hyperpolarized ${ }^{13} \mathrm{C},{ }^{15} \mathrm{~N}_{2}$-urea MRI for assessment of the urea gradient in the porcine kidney. Magn Reson Med 2016; 76:1895-1899.

34. Abragam A, Goldman M. Principles of dynamic nuclear polarisation. Rep Prog Phys 1978; 41:395-467.

35. Lumata L, Merritt ME, Malloy CR, Sherry AD, Kovacs Z. Impact of $\mathrm{Gd}^{3+}$ on DNP of $\left[1-{ }^{13} \mathrm{C}\right]$ pyruvate doped with trityl OX063, BDPA, or 4-oxo-TEMPO. J Phys Chem A 2012; 116:5129-5138.

36. Ardenkjaer-Larsen JH, Macholl $\mathrm{S}$, Jóhannesson $\mathrm{H}$. Dynamic nuclear polarization with Trityls at $1.2 \mathrm{~K}$. Appl Magn Reson 2008; 34:509-522.

37. Wenckebach T. Essentials of dynamic nuclear polarization. The Netherlands: Spindrift Publications, 2016; 296.

38. Overhauser AW. Polarization of nuclei in metals. Phys Rev 1953; 92:411-415.

39. Comment A, van den Brandt B, Uffmann K, et al. Design and performance of a DNP prepolarizer coupled to a rodent MRI scanner. Concepts Magn Reson Part B Magn Reson Eng 2007; 31B:255-269.

40. Ardenkjaer-Larsen JH, Bowen S, Petersen JR, et al. Cryogenfree dissolution dynamic nuclear polarization polarizer operating at 3.35 T, 6.70 T, and 10.1 T. Magn Reson Med 2019; 81:2184-2194.

41. Hövener JB, Pravdivtsev AN, Kidd B, et al. Parahydrogenbased hyperpolarization for biomedicine. Angew Chem Int Ed Engl 2018; 57:11140-11162.

42. Buljubasich L, Franzoni MB, Münnemann K. Parahydrogen Induced polarization by homogeneous catalysis: theory and applications. Top Curr Chem 2013; 328:33-74.

43. Pravica MG, Weitekamp DP. Net NMR alignment by adiabatic transport of parahydrogen addition products 
to high magnetic field. Chem Phys Lett 1988; 145: 255-258.

44. Dechent JF, Buljubasich L, Schreiber LM, Spiess HW, Münnemann K. Proton magnetic resonance imaging with para-hydrogen induced polarization. Phys Chem Chem Phys 2012; 14:2346-2352.

45. Kovtunov KV, Barskiy DA, Coffey AM, et al. Highresolution $3 \mathrm{D}$ proton $\mathrm{MRI}$ of hyperpolarized gas enabled by parahydrogen and $\mathrm{Rh} / \mathrm{TiO}_{2}$ heterogeneous catalyst. Chemistry 2014; 20:11636-11639.

46. Haake M, Natterer J, Bargon J. Efficient NMR pulse sequences to transfer the parahydrogen-induced polarization to hetero nuclei. J Am Chem Soc 1996; 118:8688-8691.

47. Goldman M, Jóhannesson $H$. Conversion of a proton pair para order into ${ }^{13} \mathrm{C}$ polarization by rf irradiation, for use in MRI. Comp Rend Phys 2005; 6:575-581.

48. Kadlecek S, Emami K, Ishii M, Rizi R. Optimal transfer of spin-order between a singlet nuclear pair and a heteronucleus. J Magn Reson 2010; 205:9-13.

49. Golman K, Axelsson $\mathrm{O}$, Jóhannesson $\mathrm{H}$, Månsson $\mathrm{S}$, Olofsson C, Petersson JS. Parahydrogen-induced polarization in imaging: subsecond (13)C angiography. Magn Reson Med 2001; 46:1-5.

50. Jóhannesson H, Axelsson O, Karlsson M. Transfer of parahydrogen spin order into polarization by diabatic field cycling. Comp Rend Phys 2004; 5:315-324.

51. Cavallari E, Carrera C, Boi T, Aime S, Reineri F. Effects of magnetic field cycle on the polarization transfer from parahydrogen to heteronuclei through long-range J-couplings. J Phys Chem B 2015; 119:10035-10041.

52. Bär S, Lange T, Leibfritz D, Hennig J, von Elverfeldt D, Hövener JB. On the spin order transfer from parahydrogen to another nucleus. J Magn Reson 2012; 225:25-35.

53. Stewart NJ, Kumeta H, Tomohiro M, Hashimoto T, Hatae $\mathrm{N}$, Matsumoto S. Long-range heteronuclear J-coupling constants in esters: implications for (13)C metabolic MRI by side-arm parahydrogen-induced polarization. J Magn Reson 2018; 296:85-92.

54. Gamliel A, Allouche-Arnon H, Nalbandian R, Barzilay CM, Gomori JM, Katz-Brull R. An apparatus for production of isotopically and spin-enriched hydrogen for induced polarization studies. Appl Magn Reson 2010; 39:329-345.

55. Hövener JB, Bär S, Leupold J, et al. A continuous-flow, high-throughput, high-pressure parahydrogen converter for hyperpolarization in a clinical setting. NMR Biomed 2013; 26:124-131.

56. Wagner S. Conversion rate of para-hydrogen to orthohydrogen by oxygen: implications for PHIP gas storage and utilization. MAGMA 2014; 27:195-199.

57. Kadlecek S, Vahdat V, Nakayama T, Ng D, Emami K, Rizi R. A simple and low-cost device for generating hyperpolarized contrast agents using parahydrogen. NMR Biomed 2011; 24:933-942.

58. Hövener JB, Chekmenev EY, Harris KC, et al. PASADENA hyperpolarization of ${ }^{13} \mathrm{C}$ biomolecules: equipment design and installation. MAGMA 2009; 22:111-121.

59. Coffey AM, Shchepin RV, Truong ML, Wilkens K, Pham W, Chekmenev EY. Open-source automated parahydrogen hyperpolarizer for molecular imaging using ${ }^{13} \mathrm{C}$ metabolic contrast agents. Anal Chem 2016; 88:8279-8288.
60. Chukanov NV, Salnikov OG, Shchepin RV, Kovtunov KV, Koptyug IV, Chekmenev EY. Synthesis of unsaturated precursors for parahydrogen-induced polarization and molecular imaging of $1-{ }^{13} \mathrm{C}$-acetates and $1-{ }^{13} \mathrm{C}$-pyruvates via side arm hydrogenation. ACS Omega 2018; 3:6673-6682.

61. Schmidt AB, Berner S, Schimpf $W$, et al. Liquid-state carbon-13 hyperpolarization generated in an MRI system for fast imaging. Nat Commun 2017; 8:14535.

62. Dang CV. Links between metabolism and cancer. Genes Dev 2012; 26:877-890.

63. Zhu A, Lee D, Shim H. Metabolic positron emission tomography imaging in cancer detection and therapy response. Semin Oncol 2011; 38:55-69.

64. Fletcher JW, Djulbegovic B, Soares HP, et al. Recommendations on the use of ${ }^{18} \mathrm{~F}$-FDG PET in oncology. J Nucl Med 2008; 49:480-508.

65. Golman K, Ardenkjaer-Larsen JH, Petersson JS, Mansson S, Leunbach I. Molecular imaging with endogenous substances. Proc Natl Acad Sci U S A 2003; 100:10435-10439.

66. Marjańska M, Iltis I, Shestov AA, et al. In vivo $13 \mathrm{C}$ spectroscopy in the rat brain using hyperpolarized [1-(13) C]pyruvate and [2-(13)C]pyruvate. J Magn Reson 2010; 206:210-218.

67. Golman K, in 't Zandt R, Thaning M. Real-time metabolic imaging. Proc Natl Acad Sci U S A 2006; 103: 11270-11275.

68. Golman K, Zandt RI, Lerche M, Pehrson R, ArdenkjaerLarsen $\mathrm{JH}$. Metabolic imaging by hyperpolarized 13C magnetic resonance imaging for in vivo tumor diagnosis. Cancer Res 2006; 66:10855-10860.

69. Warburg O. On the origin of cancer cells. Science 1956; 123:309-314.

70. Albers MJ, Bok R, Chen $\mathrm{AP}$, et al. Hyperpolarized ${ }^{13} \mathrm{C}$ lactate, pyruvate, and alanine: noninvasive biomarkers for prostate cancer detection and grading. Cancer Res 2008; 68:8607-8615.

71. Xu HN, Kadlececk S, Profka H, Glickson JD, Rizi R, Li LZ. Is higher lactate an indicator of tumor metastatic risk? A pilot MRS study using hyperpolarized (13)C-pyruvate. Acad Radiol 2014; 21:223-231.

72. Keshari KR, Sriram R, Koelsch BL, et al. Hyperpolarized ${ }^{13} \mathrm{C}$-pyruvate magnetic resonance reveals rapid lactate export in metastatic renal cell carcinomas. Cancer Res 2013; 73:529-538.

73. Hu S, Balakrishnan A, Bok RA, et al. ${ }^{13}$ C-pyruvate imaging reveals alterations in glycolysis that precede c-Myc-induced tumor formation and regression. Cell Metab 2011; 14 : 131-142.

74. Day SE, Kettunen MI, Gallagher FA, et al. Detecting tumor response to treatment using hyperpolarized ${ }^{13} \mathrm{C}$ magnetic resonance imaging and spectroscopy. Nat Med 2007; 13:1382-1387.

75. Chen AP, Chu W, Gu YP, Cunningham $\mathrm{CH}$. Probing early tumor response to radiation therapy using hyperpolarized $\left[1-{ }^{13} \mathrm{C}\right]$ pyruvate in MDA-MB-231 Xenografts. PLoS One 2013; 8:e56551.

76. Saito K, Matsumoto S, Takakusagi $\mathrm{Y}$, et al. ${ }^{13} \mathrm{C}-\mathrm{MR}$ spectroscopic imaging with hyperpolarized $\left[1-{ }^{13} \mathrm{C}\right]$ pyruvate detects early response to radiotherapy in SCC tumors and HT-29 tumors. Clin Cancer Res 2015; 21:5073-5081. 
77. Park I, Bok R, Ozawa T, et al. Detection of early response to temozolomide treatment in brain tumors using hyperpolarized ${ }^{13} \mathrm{C}$ MR metabolic imaging. J Magn Reson Imaging 2011; 33:1284-1290.

78. Dutta P, Le A, Vander Jagt DL, et al. Evaluation of LDH-A and glutaminase inhibition in vivo by hyperpolarized ${ }^{13} \mathrm{C}$-pyruvate magnetic resonance spectroscopy of tumors. Cancer Res 2013; 73:4190-4195.

79. Witney TH, Kettunen MI, Day SE, et al. A comparison between radiolabeled fluorodeoxyglucose uptake and hyperpolarized ${ }^{13} \mathrm{C}$-labeled pyruvate utilization as methods for detecting tumor response to treatment. Neoplasia 2009; 11:574-582.

80. Cunningham $\mathrm{CH}$, Lau JYC, Chen AP, et al. Hyperpolarized ${ }^{13} \mathrm{C}$ metabolic MRI of the human heart. Circ Res 2016; 119:1177-1182.

81. Grist JT, McLean MA, Riemer F, et al. Quantifying normal human brain metabolism using hyperpolarized $\left[1-{ }^{13} \mathrm{C}\right]$ pyruvate and magnetic resonance imaging. Neuroimage 2019; 189:171-179.

82. Aggarwal R, Vigneron DB, Kurhanewicz J. Hyperpolarized $1-\left[{ }^{13} \mathrm{C}\right]$-pyruvate Magnetic resonance imaging detects an early metabolic response to androgen ablation therapy in prostate cancer. Eur Urol 2017; 72:1028-1029.

83. Zhu Z, Marco-Rius I, Ohliger MA, et al. Hyperpolarized ${ }^{13} \mathrm{C}$ dynamic breath-held molecular imaging to detect targeted therapy response in patients with liver metastases. In: International Society for Magnetic Resonance in Medicine, Hawaii. 2017; p. 1115.

84. Park I, Larson PEZ, Gordon JW, et al. Development of methods and feasibility of using hyperpolarized carbon-13 imaging data for evaluating brain metabolism in patient studies. Magn Reson Med 2018; 80:864-873.

85. Miloushev VZ, Granlund KL, Boltyanskiy R, et al. Metabolic imaging of the human brain with hyperpolarized ${ }^{13} \mathrm{C}$ pyruvate demonstrates ${ }^{13} \mathrm{C}$ Lactate production in brain tumor patients. Cancer Res 2018; 78:3755-3760.

86. Woitek R, McLean MA, Grist JT, et al. Imaging metabolic heterogeneity in breast cancer using hyperpolarized ${ }^{13}$ C-MRSI. In: International Society for Magnetic Resonance in Medicine, Montreal. 2019; p. 0258.

87. Villanueva-Mayer J, Autry A, Gordon J, et al. Serial HP $\left[1-{ }^{13} \mathrm{C}\right]$ pyruvate and $1 \mathrm{H}$ metabolic imaging in multiply recurrent high-grade glioma. In: International Society for Magnetic Resonance in Medicine, Montreal. 2019; p. 2868.

88. Autry AW, Gordon JW, Chen HY, et al. Serial characterization of HP $\left[1-{ }^{13} \mathrm{C}\right]$ pyruvate metabolism in the brains of patients with glioma and healthy controls. In: International Society for Magnetic Resonance in Medicine, Montreal. 2019; p. 0860.

89. Gutte $H$, Hansen $A E$, Larsen $M M$, et al. Simultaneous hyperpolarized ${ }^{13} \mathrm{C}$-pyruvate MRI and ${ }^{18} \mathrm{~F}$-FDG PET (HyperPET) in 10 dogs with cancer. J Nucl Med 2015; 56:1786-1792.

90. Gutte H, Hansen AE, Henriksen ST, et al. Simultaneous hyperpolarized (13)C-pyruvate MRI and (18)F-FDG-PET in cancer (hyperPET): feasibility of a new imaging concept using a clinical PET/MRI scanner. Am J Nucl Med Mol Imaging 2015; 5:38-45.

91. Daniels CJ, McLean MA, Schulte RF, et al. A comparison of quantitative methods for clinical imaging with hyperpolarized ${ }^{(13)}$ C-pyruvate. NMR Biomed 2016; 29:387-399.
92. Harrison C, Yang C, Jindal A, et al. Comparison of kinetic models for analysis of pyruvate-to-lactate exchange by hyperpolarized ${ }^{13} \mathrm{C}$ NMR. NMR Biomed 2012; 25: 1286-1294.

93. Harris T, Eliyahu G, Frydman L, Degani H. Kinetics of hyperpolarized ${ }^{13} \mathrm{C} 1$-pyruvate transport and metabolism in living human breast cancer cells. Proc Natl Acad Sci U S A 2009; 106:18131-18136.

94. Keshari KR, Wilson DM. Chemistry and biochemistry of ${ }^{13} \mathrm{C}$ hyperpolarized magnetic resonance using dynamic nuclear polarization. Chem Soc Rev 2014; 43:1627-1659.

95. Schroeder MA, Lau AZ, Chen AP, et al. Hyperpolarized ${ }^{13} \mathrm{C}$ magnetic resonance reveals early- and late-onset changes to in vivo pyruvate metabolism in the failing heart. Eur J Heart Fail 2013; 15:130-140.

96. Hu S, Yoshihara HAI, Bok R, et al. Use of hyperpolarized $\left[1-{ }^{13} \mathrm{C}\right]$ pyruvate and $\left[2-{ }^{13} \mathrm{C}\right]$ pyruvate to probe the effects of the anticancer agent dichloroacetate on mitochondrial metabolism in vivo in the normal rat. Magn Reson Imaging 2012; 30:1367-1372.

97. Chung BT, Chen HY, Gordon J, et al. First hyperpolarized $\left[2-{ }^{13} \mathrm{C}\right]$ pyruvate MR studies of human brain metabolism. J Magn Reson 2019; 309:106617.

98. Johansson E, Månsson S, Wirestam R, et al. Cerebral perfusion assessment by bolus tracking using hyperpolarized ${ }^{13} \mathrm{C}$. Magn Reson Med 2004; 51:464-472.

99. von Morze C, Larson PEZ, Hu S, et al. Imaging of blood flow using hyperpolarized $\left[{ }^{13} \mathrm{C}\right]$ urea in preclinical cancer models. J Magn Reson Imaging 2011; 33:692-697.

100. Lau AZ, Miller JJ, Robson MD, Tyler DJ. Simultaneous assessment of cardiac metabolism and perfusion using copolarized $\left[1-{ }^{13} \mathrm{C}\right]$ pyruvate and ${ }^{13} \mathrm{C}$-urea. Magn Reson Med 2017; 77:151-158.

101. Reed GD, von Morze C, Bok R, et al. High resolution ${ }^{13} \mathrm{C}$ MRI with hyperpolarized urea: in vivo $\mathrm{T}_{2}$ mapping and ${ }^{15} \mathrm{~N}$ labeling effects. IEEE Trans Med Imaging 2014; 33:362-371.

102. Laustsen C, Stokholm Nørlinger T, Christoffer Hansen $\mathrm{D}$, et al. Hyperpolarized ${ }^{13} \mathrm{C}$ urea relaxation mechanism reveals renal changes in diabetic nephropathy. Magn Reson Med. 2016; 75:515-518.

103. Gallagher FA, Kettunen MI, Hu DE, et al. Production of hyperpolarized $\left[1,4-{ }^{13} \mathrm{C} 2\right]$ malate from $\left[1,4-{ }^{13} \mathrm{C} 2\right]$ fumarate is a marker of cell necrosis and treatment response in tumors. Proc Natl Acad Sci U S A 2009; 106: 19801-19806.

104. Miller JJ, Lau AZ, Nielsen PM, et al. Hyperpolarized $\left[1,4-{ }^{13} \mathrm{C} 2\right]$ fumarate enables magnetic resonance-based imaging of myocardial necrosis. JACC CardiovasC Imaging 2018; 11:1594-1606.

105. Clatworthy MR, Kettunen MI, Hu DE, et al. Magnetic resonance imaging with hyperpolarized [1,4-(13)C2]fumarate allows detection of early renal acute tubular necrosis. Proc Natl Acad Sci U S A 2012; 109:13374-13379.

106. Witney TH, Kettunen MI, Hu DE, et al. Detecting treatment response in a model of human breast adenocarcinoma using hyperpolarised $\left[1-{ }^{13} \mathrm{C}\right]$ pyruvate and $\left[1,4-{ }^{13} \mathrm{C} 2\right]$ fumarate. Br J Cancer 2010; 103:1400-1406.

107. Eldirdiri A, Clemmensen A, Bowen S, Kjær A, ArdenkjærLarsen $\mathrm{JH}$. Simultaneous imaging of hyperpolarized $\left[1,4-{ }^{13} \mathrm{C}_{2}\right]$ fumarate, $\left[1-{ }^{13} \mathrm{C}\right]$ pyruvate and ${ }^{18} \mathrm{~F}-\mathrm{FDG}$ in a rat 
model of necrosis in a clinical PET/MR scanner. NMR Biomed 2017; 30. doi: 10.1002/nbm.3803.

108. Bohndiek SE, Kettunen MI, Hu DE, et al. Hyperpolarized $\left[1-{ }^{13} \mathrm{C}\right]$-ascorbic and dehydroascorbic acid: vitamin $\mathrm{C}$ as a probe for imaging redox status in vivo. J Am Chem Soc 2011; 133:11795-11801.

109. Keshari KR, Kurhanewicz J, Bok R, Larson PEZ, Vigneron DB, Wilson DM. Hyperpolarized ${ }^{13} \mathrm{C}$ dehydroascorbate as an endogenous redox sensor for in vivo metabolic imaging. Proc Natl Acad Sci U S A 2011; 108:18606-18611.

110. Keshari KR, Wilson DM, Sai V, et al. Noninvasive in vivo imaging of diabetes-induced renal oxidative stress and response to therapy using hyperpolarized ${ }^{13} \mathrm{C}$ dehydroascorbate magnetic resonance. Diabetes 2015; 64:344-352.

111. Baligand C, Qin H, True-Yasaki A, et al. Hyperpolarized ${ }^{13} \mathrm{C}$ magnetic resonance evaluation of renal ischemia reperfusion injury in a murine model. NMR Biomed 2017; 30. doi: 10.1002/nbm.3765.

112. Gallagher FA, Kettunen MI, Brindle KM. Imaging pH with hyperpolarized ${ }^{13} \mathrm{C}$. NMR Biomed 2011; 24:1006-1015.

113. Gallagher FA, Kettunen MI, Day SE, et al. Magnetic resonance imaging of $\mathrm{pH}$ in vivo using hyperpolarized ${ }^{13}$ C-labelled bicarbonate. Nature 2008; 453:940-943.

114. Schroeder MA, Swietach P, Atherton HJ, et al. Measuring intracellular $\mathrm{pH}$ in the heart using hyperpolarized carbon dioxide and bicarbonate: ${ }^{13} \mathrm{C}$ and ${ }^{31} \mathrm{P}$ magnetic resonance spectroscopy study. Cardiovasc Res 2010; 86: 82-91.

115. Lau AZ, Miller JJ, Tyler DJ. Mapping of intracellular $\mathrm{pH}$ in the in vivo rodent heart using hyperpolarized $\left[1-{ }^{13} \mathrm{C}\right]$ pyruvate. Magn Reson Med 2017; 77:1810-1817.

116. Düwel S, Hundshammer C, Gersch M, et al. Imaging of $\mathrm{pH}$ in vivo using hyperpolarized ${ }^{13} \mathrm{C}$-labelled zymonic acid. Nat Commun 2017; 8:15126.

117. Chaumeil MM, Larson PEZ, Woods SM, et al. Hyperpolarized $\left[1-{ }^{13} \mathrm{C}\right]$ glutamate: a metabolic imaging biomarker of IDH1 mutational status in glioma. Cancer Res 2014; 74:4247-4257.

118. Harris T, Degani H, Frydman L. Hyperpolarized ${ }^{13} \mathrm{C}$ NMR studies of glucose metabolism in living breast cancer cell cultures. NMR Biomed 2013; 26:1831-1843.

119. Rodrigues TB, Serrao EM, Kennedy BW, Hu DE, Kettunen $\mathrm{MI}$, Brindle KM. Magnetic resonance imaging of tumor glycolysis using hyperpolarized ${ }^{13} \mathrm{C}$-labeled glucose. Nat Med 2014; 20:93-97.

120. Koellisch U, Gringeri CV, Rancan G, et al. Metabolic imaging of hyperpolarized $\left[1-{ }^{13} \mathrm{C}\right]$ acetate and $\left[1-{ }^{13} \mathrm{C}\right]$ acetylcarnitine investigation of the influence of dobutamine induced stress. Magn Reson Med 2015; 74:1011-1018.

121. Flori A, Liserani M, Frijia F, et al. Real-time cardiac metabolism assessed with hyperpolarized $\left[1-{ }^{13} \mathrm{C}\right]$ acetate in a large-animal model. Contrast Media Mol Imaging 2015; 10:194-202.

122. Bastiaansen JAM, Cheng T, Mishkovsky M, Duarte JMN, Comment A, Gruetter R. In vivo enzymatic activity of acetylCoA synthetase in skeletal muscle revealed by $13 \mathrm{C}$ turnover from hyperpolarized $\left[1-{ }^{13} \mathrm{C}\right]$ acetate to $\left[1-{ }^{13}\right.$ C]acetylcarnitine. Biochim Biophys Acta 2013; 1830: 4171-4178.
123. Reineri F, Viale A, Dastrù W, Gobetto R, Aime S. How to design ${ }^{13} \mathrm{C}$ para-hydrogen-induced polarization experiments for MRI applications. Contrast Media Mol Imaging 2011; 6:77-84.

124. Bhattacharya $\mathrm{P}$, Chekmenev EY, Perman $\mathrm{WH}$, et al. Towards hyperpolarized ${ }^{13} \mathrm{C}$-succinate imaging of brain cancer. J Magn Reson 2007; 186:150-155.

125. Chekmenev EY, Hövener J, Norton VA, et al. PASADENA hyperpolarization of succinic acid for MRI and NMR spectroscopy. J Am Chem Soc 2008; 130:4212-4213.

126. Zacharias NM, McCullough CR, Wagner S, et al. Towards real-time metabolic profiling of cancer with hyperpolarized succinate. J Mol Imaging Dyn 2016;6. pii: 123.

127. Zacharias NM, Chan HR, Sailasuta N, Ross BD, Bhattacharya P. Real-time molecular imaging of tricarboxylic acid cycle metabolism in vivo by hyperpolarized $1-{ }^{13} \mathrm{C}$ diethyl succinate. J Am Chem Soc 2012; 134:934-943.

128. Goldman $M$, Jóhannesson $H$, Axelsson $O$, Karlsson $M$. Hyperpolarization of ${ }^{13} \mathrm{C}$ through order transfer from parahydrogen: a new contrast agent for MRI. Magn Reson Imaging 2005; 23:153-157.

129. Bhattacharya P, Harris K, Lin AP, et al. Ultra-fast three dimensional imaging of hyperpolarized ${ }^{13} \mathrm{C}$ in vivo. MAGMA 2005; 18:245-256.

130. Schmidt $A B$, Berner $S$, Braig $M$, et al. In vivo ${ }^{13} \mathrm{C}-\mathrm{MRI}$ using SAMBADENA. PLoS One 2018; 13:e0200141.

131. Goldman $M$, Jóhannesson $H$, Axelsson $O$, Karlsson $M$. Design and implementation of ${ }^{13} \mathrm{C}$ hyper polarization from para-hydrogen, for new MRI contrast agents. Comp Rend Chim 2006; 9:357-363.

132. Cai C, Coffey AM, Shchepin RV, Chekmenev EY, Waddell KW. Efficient transformation of parahydrogen spin order into heteronuclear magnetization. J Phys Chem B 2013; 117:1219-1224.

133. Bhattacharya P, Chekmenev EY, Reynolds WF, et al. Parahydrogen-induced polarization (PHIP) hyperpolarized MR receptor imaging in vivo: a pilot study of ${ }^{13} \mathrm{C}$ imaging of atheroma in mice. NMR Biomed 2011; 24:1023-1028.

134. Hurd RE, Yen YF, Mayer D, et al. Metabolic imaging in the anesthetized rat brain using hyperpolarized $\left[1-{ }^{13} \mathrm{C}\right]$ pyruvate and $\left[1-{ }^{13} \mathrm{C}\right]$ ethyl pyruvate. Magn Reson Med 2010; 63:1137-1143.

135. Shchepin RV, Coffey AM, Waddell KW, Chekmenev EY. PASADENA hyperpolarized ${ }^{13} \mathrm{C}$ phospholactate. J Am Chem Soc 2012; 134:3957-3960.

136. Shchepin RV, PhamW, ChekmenevEY. Dephosphorylation and biodistribution of $1-{ }^{13} \mathrm{C}$-phospholactate in vivo. J Labelled Comp Radiopharm 2014; 57:517-524.

137. Shchepin RV, Coffey AM, Waddell KW, Chekmenev EY. Parahydrogen induced polarization of $1-{ }^{13} \mathrm{C}$-phospholactate- $d_{2}$ for biomedical imaging with $>30,000,000$ fold NMR signal enhancement in water. Anal Chem 2014; 86:5601-5605.

138. Reineri F, Santelia D, Viale A, et al. Para-hydrogenated glucose derivatives as potential ${ }^{13} \mathrm{C}$-hyperpolarized probes for magnetic resonance imaging. J Am Chem Soc 2010; 132:7186-7193.

139. Reineri F, Viale A, Ellena S, et al. ${ }^{15} \mathrm{~N}$ Magnetic resonance hyperpolarization via the reaction of parahydrogen 
with ${ }^{15} \mathrm{~N}$-propargylcholine. J Am Chem Soc 2012; 134 : 11146-11152.

140. Shchepin RV, Chekmenev EY. Synthetic approach for unsaturated precursors for parahydrogen induced polarization of choline and its analogs. J Label Compd Radiopharm 2013; 56:655-662.

141. McCormick J, Korchak S, Mamone S, et al. More than $12 \%$ polarization and 20 minute lifetime of ${ }^{15} \mathrm{~N}$ in a choline derivative utilizing parahydrogen and a rhodium nanocatalyst in water. Angew Chem Int Ed Engl 2018; 57:10692-10696.

142. Reineri F, Boi T, Aime S. ParaHydrogen induced polarization of ${ }^{13} \mathrm{C}$ carboxylate resonance in acetate and pyruvate. Nat Commun 2015; 6:5858.

143. Cavallari E, Carrera C, Aime S, Reineri F. ${ }^{13} \mathrm{C}$ MR hyperpolarization of lactate by using parahydrogen and metabolic transformation in vitro. Chemistry 2017; 23: 1200-1204.

144. Cavallari E, Carrera C, Aime S, Reineri F. Studies to enhance the hyperpolarization level in PHIP-SAH-produced C13pyruvate. J Magn Reson 2018; 289:12-17.

145. Cavallari E, Carrera C, Sorge $M$, et al. The ${ }^{13} \mathrm{C}$ hyperpolarized pyruvate generated by ParaHydrogen detects the response of the heart to altered metabolism in real time. Sci Rep 2018; 8:8366.

146. Salnikov OG, Chukanov NV, Shchepin RV, et al. Parahydrogen-induced polarization of $1-{ }^{13} \mathrm{C}$-acetates and $1-{ }^{13} \mathrm{C}$-pyruvates using sidearm hydrogenation of vinyl, allyl, and propargyl esters. J Phys Chem C Nanomater Interfaces 2019; 123:12827-12840.

147. Korchak S, Mamone S, Glöggler S. Over $50 \%{ }^{1} \mathrm{H}$ and ${ }^{4} \mathrm{C}$ polarization for generating hyperpolarized metabolitesa para-hydrogen approach. ChemistryOpen 2018; 7 : 672-676.

148. Wilson DM, Keshari KR, Larson PE, et al. Multicompound polarization by DNP allows simultaneous assessment of multiple enzymatic activities in vivo. J Magn Reson 2010; 205:141-147.

149. Cho A, Eskandari R, Granlund KL, Keshari KR. Hyperpolarized $\left[6-{ }^{13} \mathrm{C},{ }^{15} \mathrm{~N} 3\right]$-arginine as a probe for in vivo arginase activity. ACS Chem Biol 2019; 14:665-673.

150. Moreno KX, Harrison CE, Merritt ME, Kovacs Z, Malloy $\mathrm{CR}$, Sherry AD. Hyperpolarized $\delta\left[1{ }^{13} \mathrm{C}\right]$ gluconolactone as a probe of the pentose phosphate pathway. NMR Biomed 2017; 30:e3713.

151. Park JM, Wu M, Datta K, et al. Hyperpolarized sodium $\left[1-{ }^{13} \mathrm{C}\right]$-glycerate as a probe for assessing glycolysis in vivo. J Am Chem Soc 2017; 139:6629-6634.

152. Ardenkjaer-Larsen $\mathrm{JH}$. On the present and future of dissolution-DNP. J Magn Reson 2016; 264:3-12.

153. Glöggler S, Grunfeld AM, Ertas YN, et al. A nanoparticle catalyst for heterogeneous phase para-hydrogen-induced polarization in water. Angew Chem Int Ed Engl 2015; 54:2452-2456.

154. Leutzsch $M$, Wolf LM, Gupta $P$, et al. Formation of ruthenium carbenes by gem-hydrogen transfer to internal alkynes: implications for alkyne trans-hydrogenation. Angew Chem Int Ed Engl 2015; 54:12431-12436.

155. Ripka B, Eills J, Kouřilová $H$, Leutzsch $M$, Levitt $M H$, Münnemann K. Hyperpolarized fumarate via parahydrogen. Chem Commun 2018; 54:12246-12249.

156. Barskiy DA, Ke LA, Li X, et al. Rapid catalyst capture enables metal-free para-hydrogen-based hyperpolarized contrast agents. J Phys Chem Lett 2018; 9:2721-2724.

157. Bales LB, Kovtunov KV, Barskiy DA, et al. Aqueous, heterogeneous para-hydrogen-induced ${ }^{15} \mathrm{~N}$ polarization. J Phys Chem C 2017; 121:15304-15309.

158. Nonaka H, Hirano M, Imakura Y, Takakusagi Y, Ichikawa $\mathrm{K}$, Sando S. Design of a ${ }^{15} \mathrm{~N}$ molecular unit to achieve long retention of hyperpolarized spin state. Sci Rep 2017; 7:40104.

159. Kuhn LT, Bommerich $U$, Bargon J. Transfer of parahydrogen-induced hyperpolarization to ${ }^{19} \mathrm{~F}$. J Phys Chem A 2006; 110:3521-3526.

160. Bouchard LS, Kovtunov KV, Burt SR, et al. Para-hydrogenenhanced hyperpolarized gas-phase magnetic resonance imaging. Angew Chem Int Ed Engl 2007; 46: 4064-4068.

161. Kovtunov KV, Truong ML, Barskiy DA, et al. Propane- $d_{6}$ heterogeneously hyperpolarized by parahydrogen. J Phys Chem C 2014; 118:28234-28243.

162. Hövener JB, Schwaderlapp N, Borowiak R, et al. Toward biocompatible nuclear hyperpolarization using signal amplification by reversible exchange: quantitative in situ spectroscopy and high-field imaging. Anal Chem 2014; 86:1767-1774.

163. Hurd RE, Yen YF, Chen A, Ardenkjaer-Larsen JH. Hyperpolarized ${ }^{13} \mathrm{C}$ metabolic imaging using dissolution dynamic nuclear polarization. J Magn Reson Imaging 2012; 36:1314-1328.

164. Kohler SJ, Yen Y, Wolber J, et al. In vivo 13 carbon metabolic imaging at 3T with hyperpolarized ${ }^{13} \mathrm{C}-1$-pyruvate. Magn Reson Med 2007; 58:65-69.

165. Josan S, Hurd R, Park JM, et al. Dynamic metabolic imaging of hyperpolarized $\left[2-{ }^{13} \mathrm{C}\right]$ pyruvate using spiral chemical shift imaging with alternating spectral band excitation. Magn Reson Med 2014; 71:2051-2058.

166. Salamanca-Cardona L, Keshari KR. ${ }^{13}$ C-labeled biochemical probes for the study of cancer metabolism with dynamicnuclearpolarization-enhancedmagneticresonance imaging. Cancer Metab 2015; 3:9.

167. Park JM, Josan S, Grafendorfer T, et al. Measuring mitochondrial metabolism in rat brain in vivo using MR spectroscopy of hyperpolarized $\left[2-{ }^{13} \mathrm{C}\right]$ pyruvate. NMR Biomed 2013; 26:1197-1203. 